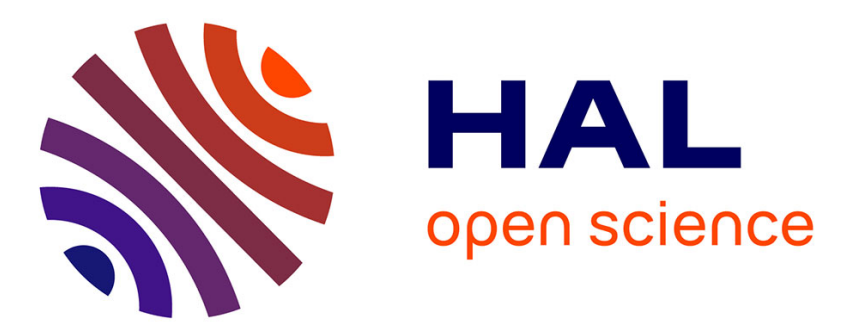

\title{
Guaiacol and its mixtures: new data and predictive models Part 1: Phase equilibrium
}

C. Pereira, C. Féjean, S. Betoulle, Nicolas Ferrando, Rafael Lugo, J.C. de Hemptinne, P. Mougin

\section{- To cite this version:}

C. Pereira, C. Féjean, S. Betoulle, Nicolas Ferrando, Rafael Lugo, et al.. Guaiacol and its mixtures: new data and predictive models Part 1: Phase equilibrium. Fluid Phase Equilibria, 2018, 470, pp.75 - 90. 10.1016/j.fluid.2018.01.035 . hal-01904130

\section{HAL Id: hal-01904130 \\ https://hal-ifp.archives-ouvertes.fr/hal-01904130}

Submitted on 24 Oct 2018

HAL is a multi-disciplinary open access archive for the deposit and dissemination of scientific research documents, whether they are published or not. The documents may come from teaching and research institutions in France or abroad, or from public or private research centers.
L'archive ouverte pluridisciplinaire HAL, est destinée au dépôt et à la diffusion de documents scientifiques de niveau recherche, publiés ou non, émanant des établissements d'enseignement et de recherche français ou étrangers, des laboratoires publics ou privés. 


\title{
Guaiacol and its mixtures: new data and predictive models
}

Part 1: Phase equilibrium

\author{
Pereira, C.G. ${ }^{1,2^{*}}$, Féjean C. ${ }^{1}$, Betoulle S. ${ }^{1}$, Ferrando N. ${ }^{1}$, Lugo, R. ${ }^{1}$, Hemptinne, \\ J.C. ${ }^{1}$, Mougin, P. $^{1}$ \\ ${ }^{1}$ IFP Energies nouvelles, 1 - 4 avenue de Bois-Préau, 92852 Rueil-Malmaison, France \\ ${ }^{2}$ UFRN- Federal University of Rio Grande do Norte, Natal, Brazil
}

\begin{abstract}
In the present work, new experimental data of guaiacol mixture with methane were investigated. The results have been evaluated using several thermodynamic approaches. Predictive calculations using the GC-PPC-SAFT (Group Contribution-Polar Perturbed ChainStatistical Associating Fluid Theory) equation of state and Molecular Simulation using the AUA4 force field were performed. Data from literature for the binary systems of guaiacol with $\mathrm{CO}_{2}$, ethanol, octanol, acetone, butyl acetate and water were used to evaluate the thermodynamic models. The effect of the association scheme is discussed at length. Predictive phase equilibrium for systems containing small toxic compounds, such as hydrogen, carbon monoxide, hydrogen sulfide and ammonia were also performed. In GC-PPC-SAFT, two configurations of associative sites for guaiacol were considered. The predicted values showed to be consistent with new experimental data. The effect of conformational structure of guaiacol on phase equilibria was detected.
\end{abstract}

Keywords: phase equilibria, guaiacol, GC-PPC-SAFT, molecular simulation

\section{INTRODUCTION}

The increase in the energy demand coupled with the gradual depletion of fossil fuels and the political and environmental requirements have motivated the search of new energy sources. Recently, the biomass conversion into hydrocarbon fuels has gained special attention due to its attractive characteristics in terms of availability and sustainability. 
The use of bioresources in the production of energy and chemicals involves major environmental, economic and geostrategic implications. Indeed, creating new opportunities for bio-products in the field of energy, chemicals and materials should lead to a reduction of greenhouse gas emissions. The general objective behind this strategy is to ensure the protection of human beings and their environment while ensuring also the continuity of the economic activities with a reduced dependence on fossil energies. Unlike fossil fuels, bioresources are renewable, widely available and better distributed throughout the world, and their valorisation will certainly have a very positive impact at the regional level on the preservation of jobs and development of rural areas [1].

Chemical and petrochemical industries are now aiming at developing new green chemistry-based processes [2], [3], and lignocellulosic biomass (LCB) is called to play a major role as an alternative raw material. Indeed, the lignocellulosic material may be conditioned to obtain already "functionalised" molecules for specific applications, unlike hydrocarbons that require additional processing steps for the synthesis of specific chemicals.

The mixtures associated with the conversion of LCB include a large number of oxygenated molecules belonging to different families produced through the decomposition of the main constituents of LCB: cellulose, hemicellulose (polymers of sugars) and lignin (phenolic-derivatives polymers). The fast pyrolysis of LCB, for instance, produces solid, liquid (bio-oil) and gaseous fractions, in which the bio-oil is a source of several attractive compounds, including lighter components from different chemical families such as carboxylic acids, ethers or ketones and heavier compounds such as phenolic or furan derivatives. Recent studies have used guaiacol (or 2-methoxyphenol) as a model compound of bio-oil due to its molecular structure: it contains two oxygen-containing functional groups (phenolic - $\mathrm{OH}$ - and methoxy $-\mathrm{OCH}_{3}$ - groups) that facilitate its repolymerization [4]-[6].

The processing and refining of these products is needed to improve their quality and to promote their use as a fuel. Several treatments can be considered: cracking, hydrocracking, decarbonylation, decarboxylation, hydrodeoxygenation, catalytic hydrotreatment, hydrogenation, others. However, in order to carry out studies on the technological and economic potential of LCB conversion process, it is necessary to develop predictive thermodynamic models with strong theoretical basis able to deal with multifunctional molecules where complex polar and associating interactions take place.

There have been several previous studies aiming at modelling systems with phenol derivatives. Lee et al [7] evaluated the phase equilibria of $\mathrm{CO}_{2}+$ guaiacol and the data was correlated by different equations of state (EOS): the Soave-Redlich-Kwong, the Peng- 
Robinson, and the Patel-Teja EOS with the van der Waals mixing rules. They all require two binary interaction parameters for a good modeling and can therefore not be called predictive. Hwang et al. [8] evaluated the phase equilibria of guaiacol + 1,2-dimethoxybenzene and guaiacol+ diphenylmethane with several versions of the UNIFAC. They were unable to predict the phase behavior of these systems, indicating that the interaction parameters of AC$\mathrm{OCH}_{3}$ binaries had to be re-evaluated. On the other hand, good data correlation were obtained using the Wilson, the NRTL, and the UNIQUAC models (not predictive). Espinosa et al. [9] applied the Group Contribution Associating Equation of State (GCA-EoS) to predict the phase equilibria of different phenol derivative systems; however, this work did not involve the mixtures evaluated here.

The GC-PPC-SAFT EoS has been used with some success on various mixtures of oxygenated compounds [10]. The objective of this study is to evaluate the GC-PPC-SAFT model and molecular simulations using the AUA4 force field, to predict the phase equilibria of systems with guaiacol. The behavior of its mixtures with associative, non- associative, polar and apolar compounds was evaluated. Phase equilibria of mixtures of guaiacol with methane, carbon dioxide, ethanol, octanol, water, acetone, butyl acetate, n-hexadecane and other light components such as $\mathrm{H}_{2}, \mathrm{CO}, \mathrm{H}_{2} \mathrm{~S}$ and $\mathrm{NH}_{3}$ were evaluated in the present work. In order to evaluate the complexity of guaiacol, an analysis of its structure was also performed.

\section{Experimental Section}

\subsection{Materials}

For carrying out the phase equilibrium experiments, the following reagents were used: methane and carbon dioxide from Air Liquide (purity $\geq 99.998 \%$ ), and guaiacol from SAFC (purity $\geq 98 \%$ ), and guaiacol from Sigma Aldrich (purity $\geq$ $99.998 \%)$.

\subsection{Apparatus and procedure}

Experimental measurements of methane + guaiacol system at $443.15 \mathrm{~K}$ were performed in an equilibrium cell with a variable volume at constant pressure. The procedure and details of the equipment and its validation are provided in Pereira et al. [11]. 


\section{Models used}

In this work, the predictions of phase envelope were done using molecular-based GCPPC-SAFT Equation of State as well as Monte Carlo Molecular Simulation with the AUA4 force field.

\subsection{GC-PPC-SAFT}

The GC-PC-SAFT EoS was originally proposed by Tamouza et al. [12] to model vapor-liquid equilibria of non-ideal mixtures. Later, Nguyen Huynh et al. [13] extended the application of this model to polar-chain containing mixtures (the so-called PPC-SAFT EoS) and applied it successfully to model the phase equilibrium behavior of different kind of chemical series, including alcohols, alkyl-benzenes, esters, ethers, ketones, aldehydes [14-16] and small gas-containing systems $[15,17,18]$.

The GC-PPC-SAFT (Group Contribution- Polar Perturbed- Chain Statistical Associating Fluid Theory) Equation of State is a predictive model developed from the polar PC-SAFT equation proposed by Gross and Sadowski [19-21], coupled to a group contribution method (CG). It is expressed as a sum of Helmholtz energy contributions:

$$
A^{\text {res }}=\left(m A^{\text {hs }}+A^{\text {chain }}\right)+A^{\text {disp }}+A^{\text {assoc }}+A^{\text {multi-polar },}
$$

where the first four terms relate to the non-polar interactions and follow the theory developed by Gross and Sadowski, the last incorporate the contribution of polar interactions that was obtained by extending the Gubbins and Twu [22] theory to chain molecules using the socalled "segment approach" of Jog \& Chapman [23], [24]. The details for the description of these terms can be found in the original papers.

\subsubsection{Pure- Components parameters}

In GC-PPC-SAFT, the segment parameters $(\varepsilon$ and $\sigma$ ) and the chain parameter $m$ of the molecule are calculated from group contribution parameters $\varepsilon_{k}, \sigma_{k}$ and $R_{k}$ using the following relations inspired by the Lorentz-Berthelot combining rules [12], [25]:

$$
\varepsilon=\sum_{k=1}^{n_{\text {groups }}} \sqrt[n_{k}]{\prod_{k=1}^{n_{\text {groups }}} \varepsilon_{k}^{n_{k}}}
$$




$$
\begin{aligned}
& \sigma=\sum_{k=1}^{n_{\text {groups }}} n_{k} \sigma_{k} / \sum_{k=1}^{n_{\text {groups }}} n_{k} \\
& \mathrm{~m}=\sum_{\mathrm{k}=1}^{\mathrm{n}_{\text {groups }}} \mathrm{n}_{\mathrm{k}} \mathrm{R}_{\mathrm{k}}
\end{aligned}
$$

where $n_{k}$ is the number of groups $k$ in the molecule that is made of $n_{\text {groups }}$ different groups.

In the case of polar compounds (water, aromatic compounds, alkanols, ...) additional parameters shall be considered: for dipolar compounds (water, alkanols), the dipole moment $\mu$ and dipole fraction $\left(x_{p}^{\mu} . m\right)$, and for quadrupolar compounds (aromatic hydrocarbons), the quadrupole moment $\mathrm{Q}$ and its corresponding quadrupolar fraction $\left(x_{p}^{Q} . m\right)$. These parameters are only relevant to polar and quadrupolar groups.

Finally, association interactions are considered using a specific term that requires additional information and parameters: an association scheme and a self-association energy $\left(\varepsilon^{A B}\right)$ and volume $\left(\kappa^{A B}\right)$. Self-association parameters are required for water and alkanols, and more generally, for all molecules containing both electron-donor and electron-acceptor sites. All the pure compounds parameters for methane, carbon dioxide, ethanol, octanol, water and small molecules $\left(\mathrm{H}_{2}, \mathrm{H}_{2} \mathrm{~S}, \mathrm{NH}_{3}, \mathrm{CO}\right)$ were already determined in previous works, by the simultaneous regression of vapor pressure and pure saturated liquid density. These parameters are presented in Table 1.

For octanol and guaiacol, the segment parameters were calculated using group contributions using the equations (2) - (4). The group parameters defined in Table 2 were used.

\section{(Insert Tables 1 and 2)}




\subsubsection{Mixture parameters}

For mixtures containing compounds of different structures and polarities, combining rules must be defined. To improve the reproduction, two interaction parameters can be considered: dispersive binary interactions parameters and cross-association parameters.

- Dispersive Binary Interactions Parameters: PC-SAFT EoS can be applied to mixtures using the van der Waals one-fluid model and the modified Lorentz-Berthelot mixing rules, through the potential parameters $\varepsilon_{i j}$ and $\sigma_{i j}$ between segments of molecules $i$ and $j$.

$$
\begin{aligned}
& \varepsilon_{i j}=\left(1-k_{i j}\right) \sqrt{\varepsilon_{i i} \varepsilon_{j j}} \\
& \sigma_{i j}=\left(\frac{\sigma_{i i}+\sigma_{j j}}{2}\right)
\end{aligned}
$$

In order to keep the predictive characteristic of the GC-PPC-SAFT model, a predictive $\mathrm{k}_{\mathrm{ij}}$ was here considered (Eq 7, [15]) for all systems with guaiacol.

$$
1-k_{i j}=\frac{2 \sqrt{J_{i} J_{j}}}{J_{i}+J_{j}}
$$

where $J_{i}$ is the pseudo-ionization energy of the molecule $i$.

- Association Interactions Parameters: PC-SAFT EoS can be applied to mixtures using

The combination rule for the cross-association parameters is as follows:

$$
\begin{aligned}
\varepsilon^{A_{\alpha} B_{\beta}} & =\frac{\varepsilon^{A_{\alpha}}+\varepsilon^{B_{\beta}}}{2} \\
\kappa^{A_{\alpha} B_{\beta}} & =\sqrt{\kappa^{A_{\alpha}} \kappa^{B_{\beta}}}
\end{aligned}
$$

They were used without any correction in this work. Note the use of the indices $\alpha$ and $\beta$ rather than $\mathrm{i}$ and $\mathrm{j}$. This is to clearly label that the parameters refer to the groups $\alpha$ and $\beta$ 
rather than to compounds. The small molecules of Table 1 can be considered single group molecules.

\subsection{Molecular Simulation}

To simulate $\mathrm{CH}_{4}, \mathrm{CO}_{2}$, ethanol, $\mathrm{H}_{2}, \mathrm{CO}, \mathrm{H}_{2} \mathrm{~S}$ and $\mathrm{NH}_{3}$, the molecular models used were those of Möller et al. [34], Harris and Young [35], Darkrim et al. [36], Perez-Pellitero et al. [37], Kristof and Liszi [38] and Eckl et al. [39], respectively. Details of these force fields are given in Table 3 .

\section{(Insert Table 3)}

To simulate guaiacol, the AUA4 force field was used. To take advantage of the transferability feature of this force field, Lennard-Jones parameters and electrostatic charges distribution were directly taken from the parameterization of alkanes [40], aromatics [41], alcohols [42] and ethers [43]. For intramolecular energy calculation, united-atoms separated by more than 3 bonds interact with a Lennard-Jones potential with the same parameters as was used for intermolecular energy calculation. Intramolecular electrostatic energy was computed using the dipole-dipole methodology introduced by Ferrando et al. [42]. Two dipoles were introduced in the guaiacol molecule: the first one was defined by the 3 electrostatic charges of the ether function, and the second one by the 3 electrostatic charges of the alcohol function. A charge belonging to a given dipole interact with all the charges of the second dipole through the Coulomb's law. Bonded and non-bonded parameters of this force field are summarized in Tables 4 and 5, respectively.

\section{(Insert Tables 4 and 5)}

The choice of a mixing rule for cross-interactions between a center of force belonging to a small gas molecule and a center of force belonging to guaiacol was not obvious. From a previous study [11], it was shown that the cross-interaction between a center of force of a phenolic compound and a center of force of the various gases studied was better represented using the classical Lorentz-Berthelot rules, except for $\mathrm{CH}_{4}$ which was better represented with the Kong rules [44]. Thus, in this work either of them was adopted according to the gas molecule considered . 
Pure guaiacol was simulated in the NVT Gibbs Ensemble [45]. In this ensemble, the two phases in equilibrium were introduced in two separate boxes without an explicit interface. When employed to study pure component equilibrium, this ensemble is applied at constant total volume of the two phases in order to respect the phase rule, the temperature and the total number of molecules being also imposed. A total number of 300 molecules was used. The average properties were computed during a production run lasting for 50 million Monte Carlo steps, one step corresponding to a single Monte Carlo move. Before each production run, a preliminary run lasting for 30 to 70 million Monte Carlo steps was carried out to achieve equilibrium. In the case of Lennard-Jones interactions, a spherical cut-off equal to half of the simulation box was used while the classical tail correction was employed [46]. For long-range electrostatic energy, the Ewald summation technique was used, with a number of reciprocal vectors $k$ equal to 7 in all three space directions and a Gaussian width $\alpha^{\text {red }}$ equal to 2 in reduced units. The different Monte Carlo moves and their corresponding attempt probabilities used during the simulations were molecular translation (20\%), molecular rotation (20\%), regrowth with configurational bias [47] (20\%), transfer of a molecule between boxes with pre-insertion bias [48] (39.5\%), and volume change (0.5\%). The amplitude of translations, rigid rotations and volume changes was adjusted during the simulation to achieve an acceptance ratio of $40 \%$ for these moves. The simulations were carried out using the GIBBS software [49] jointly developed by IFP Energies nouvelles and the Laboratoire de Chimie Physique (CNRS-Université Paris-Sud). Note that vapor pressure was calculated using the Virial equation in the vapor phase, and the molar vaporization enthalpy $h^{\text {vap }}$ with the following relationship:

$$
h^{v a p}=N_{a}\left(\frac{\left\langle U^{v a p}\right\rangle}{\left\langle N^{v a p}\right\rangle}-\frac{\left\langle U^{l i q}\right\rangle}{\left\langle N^{\text {liq }}\right\rangle}+P^{v a p}\left(\frac{\left\langle V^{v a p}\right\rangle}{\left\langle N^{v a p}\right\rangle}-\frac{\left\langle V^{l i q}\right\rangle}{\left\langle N^{l i q}\right\rangle}\right)\right)
$$

where $N_{a}$ is the Avogadro number, $P^{v a p}$ the pressure calculated in the vapor phase, and $\left\langle U^{i}\right\rangle,\left\langle N^{i}\right\rangle$ and $\left\langle V^{i}\right\rangle$ the average potential energy, total number of molecules and volume of phase $i$, respectively.

The simulations of binary mixtures gas + guaiacol were carried out in the NPT Gibbs Ensemble [50]. A total number of 700 molecules was used. The equilibrium run lasted for 50 to 200 million Monte Carlo steps, according to the temperature simulated (the lowest 
temperatures requiring a longer equilibrium step). The production run lasted for 50 to 100 million Monte Carlo steps. Other simulation parameters were identical to those previously described for pure compound simulations.

\section{Results and parameterization}

\subsection{Experimental Results}

For the system methane + guaiacol there are no experimental data from literature. Thus, measurements were carried out within this work (see Table 6), and the results are compared with models in section 5.3 below.

\section{(Insert Table 6)}

\subsection{Molecular Description}

Several researchers debate on the strong inter and intramolecular HBs of phenolic compounds such as with guaiacol (2-methoxyphenol) [51]-[57]. This is because HBs affect the total enthalpy of specific interactions between solute and solvent, and then their physical behavior.

It is known also that pure guaiacol can actually exist as a mixture of two [52] or even four [56] conformational isomers (see Figure 1). The formation of intramolecular HBs has a pronounced effect on the molecular structure and properties of molecules. However, in infinite dilution solutions, practically all molecules form intramolecular HB [56].

\section{(Insert Figure 1)}

According to Heer et al. [57] phenols are known to form intermolecular hydrogen bonds that are able to have hydrogen-bond-accepting properties. Nevertheless, when they present an ortho methoxy group, they may create intramolecular hydrogen bonds as well, that are not linear. Two possibilities of conformers were evaluated considering the lowest energy conformations: one with an intramolecular hydrogen-bond and another with no hydrogenbond. In both cases, the hydroxyl and the methoxy group are in the plane of the phenyl ring. The enthalpy difference between the two conformations, $4.4 \mathrm{kcal} / \mathrm{mol}$, was defined as the intramolecular hydrogen-bond enthalpy. 
Varfolomeev et al. [52] presented a wide evaluation on thermodynamic properties of methoxyphenols (2-methoxyphenol, 3-methoxyphenol, 4-methoxyphenol, 1,2 dimethoxybenzene, 1,3 dimethoxybenzene, 1,4 dimethoxybenzene) including standard molar enthalpies of formation, vapor pressure, vaporization enthalpies, sublimation enthalpies, and fusion enthalpies, that were used for the evaluation of inter- and intramolecular HBs of these compounds. The studies also involved thermochemical, Fourier transform infrared (FTIR)spectroscopy and quantum-chemical studies of methoxyphenols and its HBs. According to these authors, 2-methoxyphenol presented the most negative enthalpy of formation (- 247.3 $\mathrm{kJ} / \mathrm{mol}$, i.e. $7.5 \mathrm{~kJ} / \mathrm{mol}$ lower than for 3-methoxyphenol), the lowest enthalpy of vaporization (50-60.4 kJ/mol, i.e. 8-10 kJ/mol less than for 4- methoxyphenol), and enthalpy of sublimation (58.9-62.9 kJ/mol, i.e. 8-11 kJ/mol less than for 4-methoxyphenol). The reason for these differences is the intramolecular hydrogen bond observed in 2-methoxyphenol. Several experiments were performed with the different isomers and the authors demonstrated the presence of strong intramolecular HB in 2- methoxyphenol. They also evaluated the strength of the HBs in the different conformations. The difference in energy of the conformers represents the energy of intramolecular HBs. This shows the complexity observed when studying systems with 2- methoxyphenol (guaiacol).

In order to better understand this effect, the liquid phase structure of pure guaiacol was investigated using molecular simulation. A Monte Carlo simulation of pure guaiacol was carried out in the monophasic NPT ensemble at $323 \mathrm{~K}, 0.1 \mathrm{MPa}$, and the equilibrated configurations were used to analyze hydrogen bond formation in the system. Figure 2 shows the intermolecular radial distribution function ( $\mathrm{rdf}$ ) between two hydroxyl oxygen atoms (noted $\mathrm{O}(\mathrm{H})$ ), and between an ether oxygen atom (noted $\mathrm{O}$ ) and a hydroxyl oxygen atom.

\section{(Insert Figure 2)}

The $\mathrm{O}(\mathrm{H})-\mathrm{O}(\mathrm{H})$ rdf clearly exhibits a peak located at $3 \AA$ which reveals the existence of an intermolecular hydrogen bond network in the system. It is interesting to see that the $\mathrm{O}(\mathrm{H})-\mathrm{O}$ rdf does not exhibit such a peak. In other words, the hydroxyl hydrogen atom forms hydrogen bond only with the hydroxyl oxygen atom and not with the ether oxygen atom. This can be explained by the fact that the electrostatic partial charge of the ether oxygen is lower than the charge of the hydroxyl oxygen. A commonly used geometric criterion to define the presence of a hydrogen bond is the oxygen-oxygen distance that must range between the beginning of the $\operatorname{rdf}(2.5 \AA)$ and the first local minimum $(3.5 \AA)$, and simultaneously the 
$\mathrm{O}(\mathrm{H})-\mathrm{H}--\mathrm{O}(\mathrm{H})$ angle that must range between 140 and $180^{\circ}$ [58],[59],[42]. With these geometric criteria, we found a monomer fraction of 0.79 (fraction of molecules not involved in a hydrogen bond) and an average number of hydrogen bond per molecule of 0.23 . This is considerably lower than the values obtained for phenol with the same force field (average number of hydrogen bond of 1.95 and a monomer fraction close to 0 at room temperature) [42]. This phenomenon could be explained by analyzing intramolecular radial distribution functions. Figure 3 shows the intermolecular distance histogram between the ether oxygen atom $\mathrm{O}$ and the hydroxyl hydrogen $\mathrm{H}$ atom.

\section{(Insert Figure 3)}

It can be seen that all the $\mathrm{O}-\mathrm{H}$ distances range from 2.1 to $2.4 \AA$. That means that all guaiacol molecules in the bulk are in anti-syn conformation as defined in Figure 1. Such a proximity of the ether oxygen atom and the hydrogen atom can result in steric hindrance, which could explain the difficulty to form intermolecular hydrogen bond compared to phenol for example. Based on this analysis, different conformational schemes of association can be used, and two of them were considered on the GC-PPC-SAFT predictions to be evaluated in this study.

\subsection{Guaiacol pure- Components parameters}

Auger [33] has investigated this compound with the GC-PPC-SAFT model, but it appears that the behavior depends strongly on the association scheme that is selected. The association term in the model cannot describe explicitly the intra-molecular bonds. These can only be taken into account by the fact that they des-activate possible bond-formation sites. This is the approach considered here. Figure 2 shows the groups used: $1(\mathrm{OH}) ; 4\left(\mathrm{CH} \_\right.$aro $)$; 2(C_aro); 1(-O-); 1( $\left.\mathrm{CH}_{3}\right)$; 1(aromatic ring). The parameters proposed by this author are given in Table 2. The association scheme is that which is shown as scheme 2 in Figure 4. The global deviation using this parameterization is $18.9 \%$ on vapor pressure and $5.37 \%$ on molar volumes. Using a predictive approach, we can also try to compute the vapor pressure of guaiacol using the published parameters by Nguyen-Huynh et al [10], also provided in Table 2. In this case, the average deviation on vapor pressure is $23 \%$ ( $2.5 \%$ on volume). In this work, we didn't consider this to be accurate enough and tried to improve by refitting some parameters. 
As will be seen below, results are very sensitive to the association scheme. For this reason, two association schemes were considered in this work: i) Scheme 1 with 3 associating sites, one positive and one negative on the group $(\mathrm{OH})$ and one negative on the $(\mathrm{O})$ of the ether function (notice that this scheme implicitly takes into account the steric hindrance effect of intramolecular association, i.e. less associating sites in the molecule); and ii) Scheme 2 with 6 associating sites, one positive and two negative on the group $(\mathrm{OH})$, two negative on the group $(\mathrm{O})$ of the ether function and one negative on the aromatic ring. The two schemes are represented in Figure 4.

\section{(Insert Figure 4)}

In order to improve the predictions, the association parameters as well as chain length contribution of the $\mathrm{OH}$ and the $\mathrm{O}$ groups were regressed to fit pure compound data (vapor pressure and liquid volume). The predicted values were compared with experimental data from literature (DIPPR validated [60]), in terms of vapor pressure, liquid volume and enthalpy of vaporization for the pure compound, and also vapor-liquid equilibrium (VLE) for the system $\mathrm{CO}_{2}+$ guaiacol [7]. Table 7 presents these parameters adjusted considering the vapor pressure and density of guaiacol.

\section{(Insert Table 7)}

All other group parameters originate from Table 2, including those of the aromatic ring. Not unexpectedly, the larger the number of sites, the lower the values of the association parameters.

With these parameters, the vapor pressure, liquid volume and vaporization enthalpy of guaiacol were calculated accurately using GC-PPC-SAFT. Figures 5, 6 and 7 shows the deviations between the predicted values (GC-PPC-SAFT and molecular simulation) and experimental data [60]. Table 8 presents the values obtained by Molecular Simulation, and Table 9 presents the deviations for each model. It is observed that for the pure compound, the two approaches (MS and GC-PPC-SAFT) yield rather low deviations. The schemes 1 and 2 provided almost identical results: in fact, almost no difference is observed between the pure component results of the two association schemes. As will be seen later, the differences appear for the mixtures with hydrogen-bonding compounds. 
(Insert Tables 8 and 9)

(Insert Figures 5, 6 and 7)

Small deviations were also observed in molecular simulation predictions: $<5 \%$ for vapour pressure and vaporization enthalpy and only $1.3 \%$ in terms of liquid volume deviations.

\section{Discussion: mixtures computations}

The difficulty to work with guaiacol is related to its molecular structure and strong and complex interactions (inter- and intramolecular hydrogen bonds - HBs), which can occur in antagonistic manner: aiding or opposing each other [51]-[52] (more details are discussed in section 4.2). We will investigate systems that could help us understand the phenomena at hand. Therefore, we shall focus on systems with water (extremely HB), with ethanol and noctanol (moderately HB), acetone and, butyl acetate (only cross HB), n-hexadecane (no HB). We shall also have a look at some gases as methane and $\mathrm{CO}_{2}$. At the end, we shall also look at some other systems for which no data exist.

For the predictions of phase equilibria of guaiacol systems with GC-PPC-SAFT, the predictive binary interaction parameters $\left(\mathrm{k}_{\mathrm{ij}}\right)$ were used (eq. 7). For that, the pseudo-ionization energy of each component $\left(J_{\mathrm{i}}\right)$ was considered and applied in Eq. (3). The pseudo-ionization energy of guaiacol (7.76) was assumed to be equal to the pseudo-ionization energy of benzene (i.e. not computed from group contributions). For the other components, the pseudoionization energies from literature [15], [17], [18], [27], [28] were used. For ammonia, it was found in a previous work that $\mathrm{J}_{\mathrm{NH} 3}=0$ [11], [1], which means that $\mathrm{k}_{\mathrm{ij}}$ for the system $\mathrm{NH}_{3}+$ guaiacol is zero.

\subsection{Systems with water and hexadecane}

In a first instance, we can evaluate the behavior of the model on binary systems with water and with n-hexadecane. Interestingly, both systems guaiacol + water (Figures 8 and 9) and guaiacol + n-hexadecane (Figure 10) show liquid-liquid phase splits. 


\section{(Insert Figures 8 and 9)}

Figures 8 and 9 both show the very nice behavior of scheme 1 for computing the water + guaiacol phase diagram. The average deviations on water concentration in the organic phase is $7 \%$, while that of guaiacol on the aqueous phase is $29 \%$. On the other hand, scheme 2 is unable to describe the liquid-liquid phase split, and the bubble pressure is clearly underestimated.

The reason for the strong difference in behavior between the two association schemes is most probably related to the large number of possible cross-associations that are offered by scheme 2 . The more cross-association, the better the solubility behavior.

On the opposite extreme, it is possible to observe a liquid-liquid equilibrium between a fully non-associating alkane, n-hexadecane, and guaiacol. As observed in Figure 10, here both association schemes provide identical, quite reasonable results. Please note that these calculations are fully predictive, and that no SAFT model is capable of describing correctly liquid-liquid critical phenomena. We therefore focus on the quality of the phase composition away from the critical end point.

\section{(Insert Figure 10)}

\subsection{Systems with moderately hydrogen bonding systems}

Here we investigate the case of guaiacol with alcohols: ethanol and n-octanol, and with acetates or esters: acetone and butyl acetate.

The results were different for systems containing alcohol. Figures 11 and 12 show the phase envelopes for the systems ethanol + guaiacol and octanol + guaiacol with predictions using GC-PPC-SAFT at different temperatures. For these systems, the predictions using Scheme 1 provided systematically better results.

\section{(Insert Figure 11)}

For the system ethanol + guaiacol (Figure 11), a deviation of 2.5\% (disregarding data at $1.9 \times 10^{-3} \mathrm{MPa}$ ) was observed for the predicted values obtained when the Scheme 1 was 
used in GC-PPC-SAFT. The Scheme 2 tends to overestimate the solubility of ethanol in guaiacol $(\sim 7 \%)$. This overestimation was also observed for the system octanol + guaiacol. This phenomenon, which corresponds to an underestimation of the bubble pressure, can easily be explained by stronger cross-association compared to that in scheme 1. A GC description of ethanol proposed by [60] was also evaluated, but it did not provide any further improvement with respect to the molecular description used to obtain Figure 11.

\section{(Insert Figure 12)}

The acetone + guaiacol system (Figure 13) is peculiar in the sense that it shows a slightly negative deviation from ideality: the bubble pressure data are slightly smaller than the straight line connecting the pure component vapor pressures. Please note that guaiacol is solid at $290.15 \mathrm{~K}$, but an extrapolation of the DIPPR vapor pressure correlation provides the low value of $6.3 \mathrm{~Pa}$; also, a $6.5 \%$ overestimation of the acetone vapor pressure by GC-PPC-SAFT is observed, which happens to be the largest deviation of the full temperature range. This deviation is quite acceptable for a predictive model. Considering that cross-association generally yields such negative deviations from ideality, it is quite unexpected that the guaiacol association scheme with the most hydrogen-bonding sites yields a larger vapor pressure. Yet, we should recognize that the behavior of such systems is driven by a balance between selfassociation (which will yield positive deviation from ideality) and cross-association (that yields negative deviation). In addition, we can also observe that both guaiacol association schemes have only one proton-donor, and that acetone has one proton acceptor site. Hence, increasing the number of proton acceptor sites on the guaiacol results in an increase of selfassociation without increasing the cross-association. This clearly explains why the scheme 2 leads to a more positive (or less negative) deviation from ideality compared to scheme 1 .

We observe again that scheme 1 is closer to the true behavior. If we want to improve the representation of such a system, the cross-association parameters must probably be adjusted.

\section{(Insert Figure 13)}


In the guaiacol + butyl-acetate system that is shown in Figure 14, it is impossible to visualize whether a negative or a positive deviation from ideality exists. Yet, the same conclusion as for the acetone + guaiacol mixture can be drawn.

\section{(Insert Figure 14)}

\subsection{Systems with gases}

The mixtures with methane or $\mathrm{CO}_{2}$ are shown in the Figures 15 and 16. For methane, we can observe the same phenomenon as with hexadecane: both schemes provide identical results.

\section{(Insert Figure 15)}

An example for the phase envelopes for the $\mathrm{CO}_{2}+$ guaiacol system using GC-PPCSAFT and molecular simulations are presented in Figures 10. The same phenomenon is observed as with acetone, that is that scheme 2, with a large number of sites, results in larger bubble pressures (underestimation of solubilities). This can be explained in the same way as for acetone: the more guaiacol can self-associate (scheme 2), the larger its tendency to feature positive deviations from ideality. This is why the bubble pressures are larger.

Espinosa et al [9] also evaluated the $\mathrm{CO}_{2}+$ guaiacol system at the same conditions of temperature. Their results were very similar to our results for predictions with GC-PPC-SAFT using Scheme 1. The difference between the GCA EoS used by Espinosa et al [9] and the one used in this work is in the additional terms for the formation of chain and multipolar interactions.

All the investigated systems with their standard deviations are presented in Table 10.

\section{(Insert Figure 16)}

\subsection{Final discussion on the predictive quality of the GC-PPC-SAFT model with} guaiacol 
According to Table 10, the predictions made with GC-PPC-SAFT showed good agreement with experimental data, and deviations were lower than those obtained with molecular simulation predictions (Figure 16). Even though binary interactions parameters $\mathrm{k}_{\mathrm{ij}}$ were used in the GC-PPC-SAFT model, these parameters were completely predicted and the values obtained were small, keeping the predictive nature of the model.

In all cases, it is observed that scheme 1 provides better predictions.

\section{(Insert Table 10)}

The analysis that is shown here illustrates following interesting features:

- Both for pure guaiacol as for mixtures with non-associating species, the association scheme has no effect on the final result. This was exemplified by mixtures with methane and with hexadecane. In all these cases, the model was capable to reproduce, both qualitatively as quantitatively the vapor-liquid and liquid-liquid phase envelopes.

- For mixtures with compounds that can only cross-associate, i.e. when it contains only a proton acceptor, the effect of having a large number of proton acceptor sites on the guaiacol molecule (scheme 2) only results in increasing self-association without allowing for an increased cross-association (both schemes feature only one proton donor site). As a consequence, the mixture shows a stronger positive deviation from ideality for scheme 2 than for scheme 1.

- For mixtures where both compounds contain proton-donors and proton-acceptors (alcohols, and water), the fact of increasing the number of proton acceptors on the guaiacol molecule results in an increase of cross-association. As a consequence, the mixture behavior shows a decrease in its positive deviation from ideality. This can be observed on the bubble curves of mixtures with both for n-octanol and ethanol, and has an even stronger effect on mixtures with water where the scheme 2 is unable to catch the liquid-liquid equilibrium.

In all comparisons with experimental data, scheme 1 showed better predictive results (Table 10). As a conclusion, we recommend using the smaller number of association sites to represent the molecule of guaiacol, i.e, scheme 1.

\subsection{Cross-over phenomenon}


Another interesting point is shown in the calculations: the cross-over behavior of the $\mathrm{CO}_{2}+$ guaiacol system indicated by literature is also predicted by GC-PPC-SAFT predictions (Figure 17). It is observed that at low pressure, increasing temperature results in a larger solubility of guaiacol in the supercritical $\mathrm{CO}_{2}$ (due to the increase in guaiacol vapor pressure), while at high pressure, the opposite is true (because higher temperature means a lower $\mathrm{CO}_{2}$ density which in turn yields a lower solubility). This behavior is common for systems in supercritical conditions. Similar phenomena are observed in systems as 1,2 dimethoxybenzene $+\mathrm{CO}_{2}$ and p-cresol $+\mathrm{CO}_{2}$ [7] , other systems [66-70]

\section{(Insert Figure 17)}

\subsection{Other Systems}

During the processing and treatment of bio-oil, other important compounds are produced, and in the absence of data for systems with toxic compounds, we performed predictive calculations for the mixtures of guaiacol + toxic gases $\left(\mathrm{H}_{2} \mathrm{~S}, \mathrm{NH}_{3}, \mathrm{H}_{2}, \mathrm{CO}\right)$. Figures 18-21 present the predictions for these systems using GC-PPC-SAFT and molecular simulation. It is possible to observe that the model is consistent in the reproduction of phase envelopes. For $\mathrm{H}_{2} \mathrm{~S}, \mathrm{H}_{2}$ and $\mathrm{CO}$ the predictions using GC-PPC-SAFT, lead to higher solubilities of these gases in guaiacol than predicted by molecular simulation. The opposite was observed for $\mathrm{NH}_{3}$. Figure 22 provides the same type of information in terms of Henry constants (here, it was not possible to compare with molecular simulation).

\section{(Insert Figures 18 to 22)}

It is observed that for $\mathrm{H}_{2} \mathrm{~S}$ and $\mathrm{NH}_{3}$, the Henry constant is much smaller than for $\mathrm{CO}$ and $\mathrm{H}_{2}$, this means that the solubility is much larger. In addition, the slope of these two sets of gases is opposite. This was already observed in our previous paper [71] where solubility was investigated in phenol- and furan type solvents: a gas that features association sites will dissolve better, and its solubility decreases with temperature (increasing Henry constant); on the opposite, the solubility of very light, non hydrogen-bonding gases is driven by free volume available in the solvent [72], which increases with temperature: their solubility increases with temperature, or their Henry constant decreases. 


\section{Conclusions}

In this work, new experimental data of the system guaiacol- methane were presented and compared with predictive models (GC-PPC-SAFT and Molecular Simulation).

Despite the lack of experimental data, an examination of the different systems makes it possible to apprehend the predictive capacity of the model.

The use of a SAFT-type model implies the definition of an association scheme. The molecular structure of guaiacol was discussed in that perspective: it appears that intramolecular association may de-activate some proton-donor or acceptor sites. In order to mimic this, two possible schemes have been proposed and analyzed. They indicated no difference for the pure compound properties or for mixtures with non-associating species. In the presence of species featuring proton donors and proton acceptors, the larger the number of sites, the more cross-association is observed. Yet, in the presence of species that only contain proton acceptors, the scheme with the larger number of sites shows more self-association and therefore a larger positive deviation (or less negative) from ideality.

As a general conclusion, for the guaiacol, the lower number of association sites (scheme 1) provided better agreement with experimental results, including liquid-liquid equilibrium with water.

Using the model that was thus developed, a number of observations could be made related to the cross-over phenomenon in supercritical solvents and related to the solubility of gases in guaiacol.

\section{Acknowledgements}

The authors wish to acknowledge the financial support of the Tuck foundation chair for thermodynamics for biofuels, and to CNPQ (246524/2012-0) for financial support. .

\section{NOMENCLATURE}

$k_{i j}=$ binary interaction parameter

$\varepsilon=$ segment-segment interaction energy

$\sigma=$ diameter of a segment

$m=$ number of segments

$\mu=$ dipole moment 
$x_{p}{ }^{\mu} m=$ number of dipoles on the molecule

$\mathrm{Q}=$ quadrupole moment

$x_{p}{ }^{Q} m=$ number of quadrupoles on the molecule

$n_{\text {sites }}=$ number of association sites

$\varepsilon^{A B} / k=$ association energy

$\kappa^{A B}=$ association volume

$\mathrm{R}_{1-4}=$ chain fraction

$\mathrm{T}_{\mathrm{C}}=$ critical temperature

$\mathrm{P}_{\mathrm{C}}=$ critical pressure

$\omega=$ acentric factor

\section{Acknowledgment}

The authors are grateful to the Tuck foundation and to CNPQ for financial support.

\section{REFERENCES}

[1].Pasty, J. C. Les débouchés non alimentaires des produits agricoles : un enjeu pour la France et l'Union Européenne. Rapport du Conseil Economique et Social, 2004.

[2]. Dodds, D. R.; Gross, R. A. Chemicals from Biomass. Science 2007, 318, 1250-1251.

[3]. Gallezot, P. Chapter 3: Process options for the catalytic conversion of renewables into bioproducts. In: Catalysis of renewables. Wiley Interscience, 2007.

[4]. Lu, Q.; Li, W. Z.; Zhu, X. F. Overview of fuel properties of biomass fast pyrolysis oils. Energy Convers. Manag 2009, 50, 1376-1383.

[5]. Oasmaa, A.; Kuoppala, E. Solvent Fractionation Method with Brix for Rapid Characterization of Wood Fast Pyrolysis Liquids. Energy Fuels 2008, 22, 4245-4248.

[6]. Bykova, M.V.; Ermakov, D.Y.; Kaichev, V. V.; Bulavchenko, O. A.; Saraev, A. A.; Lebedev, M. Y.; Yakovlev, V. A. Ni-based sol-gel catalysts as promising systems for crude bio-oil upgrading: Guaiacol hydrodeoxygenation study. Appl. Catal B-Environ. 2012, 113-114, 296-307.

[7].Lee, M. J.; Kou, C. F.; Cheng, J. W.; Lin, H. M. Vapor-liquid equilibria for binary mixtures of carbon dioxide with 1,2-dimethoxybenzene, 2-methoxyphenol, or $p$-cresol at elevated pressures. Fluid Phase Equilib. 1999, 162, 211-224.

[8].Hwang, S. M.; Lee, M. J.; Lin, H. M. Isothermal vapor-liquid equilibria for mixtures 
composed of 1,2-dimethoxybenzene, 2-methoxyphenol, and diphenylmethane. Fluid Phase Equilib. 2001, 178, 209-223.

[9]. Espinosa, S.; Diaz, S.; Fornari, T. Extension of the group contribution associating equation of state to mixtures containing phenol, aromatic acid and aromatic ether compounds. Fluid Phase Equilib. 2005, 231, 197-210.

[10]. D. Nguyen-Huynh, de Hemptinne, Jean Charles, R. Lugo, J.-P. Passarello, P. Tobaly, Advances in Thermodynamics for Chemical Process and Product Design. Chem. Eng. Res. Des. 2014, 92, 2912-2935.

[11]. Pereira, C. G.; Grandjean, L.; Betoulle S.; Ferrando N.; Féjean C.; Lugo, R.; Hemptinne, J. C.; Mougin, P. Phase Equilibria of systems containing aromatic oxygenated compounds with $\mathrm{CH}_{4}, \mathrm{CO}_{2}, \mathrm{H}_{2}, \mathrm{H}_{2} \mathrm{~S}, \mathrm{CO}$ and $\mathrm{NH}_{3}$ : experimental data and predictions. Fluid Phase Equilib. 2014, 382, 219-234

[12]. Tamouza, S.; Passarello, J. P.; Tobaly, P.; de Hemptinne J. C. Group contribution method with SAFT EOS applied to vapor liquid equilibria of various hydrocarbon series. Fluid Phase Equilib. 2004, 222-223, 67-76.

[13]. NguyenHuynh, D.; Passarello, J. P.; Tobaly, P., de Hemptinne, J. C. Application of GC-SAFT EOS to polar systems using a segment approach. Fluid Phase Equilib. 2008, $264,62-75$.

[14]. Nguyen-Huynh, D.; Benamira, M.; Passarello, J. P.; Tobaly, P.; de Hemptinne J.C.; Application of GC-SAFT EOS to polycyclic aromatic hydrocarbons, Fluid Phase Equilib. 2007, 254, 1-2, 60-66.

[15]. Nguyen-Huynh, D.; Passarello J.P.; Tobaly, P.; de Hemptinne, J. C. Modeling Phase Equilibria of Asymmetric Mixtures Using a Group-Contribution SAFT (GC-SAFT) with a k(ij) Correlation Method Based on London's Theory. 1. Application to $\mathrm{CO} 2+n$ Alkane, Methane $+\mathrm{n}$-Alkane, and Ethane $+\mathrm{n}$-Alkane Systems. Industrial \& Engineering Chemistry Research. 2008, 47, 8847-8858.

[16]. Nguyen-Huynh, D.; Falaix A.; Passarello J. P.; Tobaly P.; de Hemptinne J. C. Predicting VLE of heavy esters and their mixtures using GC-SAFT. Fluid Phase Equilib. 2008, 264, 1-2, 184-200.

[17]. Nguyen-Huynh, D.; Tran, T.K.S.; Tamouza, S.; Passarello, J.P.; Tobaly, P.; de Hemptinne, J.C. Modeling Phase Equilibria of Asymmetric Mixtures Using a GroupContribution SAFT (GC-SAFT) with a k(ij) Correlation Method Based on London's Theory. 2. Application to Binary Mixtures Containing Aromatic Hydrocarbons, nAlkanes, $\mathrm{CO}_{2}, \mathrm{~N}_{2}$, and $\mathrm{H}_{2} \mathrm{~S}$. Ind. Eng. Chem. Res. 2008, 47 , 8859-8868. 
[18]. Tran, T. K. S.; Nguyen-Huynh, D.; Ferrando, N.; Passarello, J. P.; de Hemptinne J. C.; Tobaly P. Modeling VLE of $\mathrm{H}_{2}+$ Hydrocarbon Mixtures Using a Group Contribution SAFT with a k(ij) Correlation Method Based on London's Theory. Energ Fuels 2009, 23, 2658-2665.

[19]. Gross, J.; Sadowski, G. Application of perturbation theory to a hard-chain reference fluid: an equation of state for square well chains. Fluid Phase Equilib. 2000, 168, 183199.

[20]. Gross, J.; Sadowski, G. Perturbed-Chain SAFT: An equation of state based on a perturbation theory for chain molecules. Ind. Eng. Chem. Res. 2001, 40, 1244-1260.

[21]. Gross, J.; Sadowski, G. Application of the Perturbed-Chain SAFT Equation of State to Associating Systems. Ind. Eng. Chem. Res. 2002, 41, 22, 5510-5515.

[22]. Gubbins, K. E.; Twu C. H. Thermodynamics of Polyatomic Fluid Mixtures -1 Theory. Chem. Eng. Sci. 1978, 33, 863-878.

[23]. Jog, P.; Champman, W.G. Application of Wertheim's thermodynamic Perturbation theory to dipolar hard sphere chains. Mol. Phys 1999, 97, 3, 307-319.

[24]. Jog, P.K.; Sauer, S.G.; Blaesing, J.; Champman, W.G.; Application of Dipolar Chain Theory to the Phase Behavior of Polar Fluids and Mixtures. Ind. Eng. Chem. Res.. 2001, $40,21,4641-4648$.

[25]. Tamouza, S.; Passarello, J.P.; Tobaly, P.; de Hemptinne, J.C. Application to Binary Mixtures of a Group Contribution SAFT EOS (GC-SAFT). Fluid Phase Equilib. 2005, $228-229,409-419$.

[26]. Mourah, M, Modélisation des Equilibres de Phases Liquid-Liquid et Liquid-Vapour des Mélanges Contenant de L'eau, des alcools e des hydrocarbures. PhD Thesis, Université Paris VIII, 2009.

[27]. Nguyen-Huynh, D.; de Hemptinne, J.C.; Lugo, R.; Passarello, J.P., Tobaly, P. Modeling Liquid-Liquid and Liquid-Vapor Equilibria of Binary Systems Containing Water with an Alkane, ans Aromatic Hydrocarbon, an Alcohol or a Gas (Methane, Ethane, $\mathrm{CO}_{2}$ or $\mathrm{H}_{2} \mathrm{~S}$ ), Using Group-Contribution Polar Perturbed-Chain Statistical Associating Fluid Theory. Ind. Eng. Chem. Res.. 2011, 50, 7467-7483.

[28]. Nguyen-Huynh, D. Modélisation thermodynamique de mélanges symétriques et asymétriques de composés polaires oxygénés et/ou aromatiques par GC-SAFT, PhD Thesis, Université Paris VIII, 2008.

[29]. L. Grandjean, J.C. de Hemptinne, R. Lugo, Application of GC-PPC-SAFT Eos to ammonia and its mixtures. Fluid Phase Equilibr. 2014, 37, 159-172. 
[30]. de Hemptinne J. C., Mougin, P.; Barreau, A.; Ruffine, L.; Tamouza S., Inchekel R., Application to petroleum engineering of statistical thermodynamics - Based equations of state, Oil Gas Sci. Technol. 2006, 61, 3, 363-386.

[31]. Nguyen-Huynh, D.; Passarello, J.-P.; de Hemptinne, J.-C.; Tobaly, P. Extension of Polar GC-SAFT to Systems Containing Some Oxygenated Compounds: Application to Ethers, Aldehydes and Ketones. Fluid Phase Equilib. 2011, 307 (2), 142-159.

[32]. Nguyen Huynh, D.; Falaix, A.; Tamouza, S.; Passarello, J-P; Tobaly, P.; de Hemptinne, JC. Prediction of heavy esters and their mixtures using GC-SAFT. Fluid Phase Equilib. 2008, 264, 184-200.

[33]. Auger, E. Equilibres de phases des fluides oxygénés issus du traitement thermochimique de la biomasse lignocellulosique, 2012.

[34]. Möller, D.; Opryzynski, J.; Müller, A.; Fischer. Prediction of thermodynamic properties of fluid mixtures by molecular dynamics simulations: methane-ethane. J. Mol. Phys. 1992, 75, 363-378.

[35]. Harris, J. G.; Yung, K. H. Carbon Dioxide's Liquid-Vapor Coexistence Curve And Critical Properties as Predicted by a Simple Molecular Model. J. Phys. Chem. 1995, 99, 12021-12024.

[36]. Darkrim, F.; Vermesse, J.; Malbrunot, P.; Levesque, D. Monte Carlo simulations of nitrogen and hydrogen physisorption at high pressures and room temperature. Comparison with experiments. J. Chem. Phys. 1999, 110, 4020-4027.

[37]. Perez-Pellitero, J.; Amrouche, H.; Siperstein, F. R.; Pirngruber, G.; Nieto-Draghi, C.; Chaplais, G.; Simon-Masseron, A.; Bazer-Bachi, A.; Peralta, A.; Bats, N. Chem-Eur J. 2010, 16, 1560-1571.

[38]. Kristof, T.; Liszi, J. Effective Intermolecular Potential for Fluid Hydrogen Sulfide. J. Phys. Chem. B 1997, 101, 5480-5483.

[39]. Eckl, B.; Vrabec, J.; Hasse, H. An optimised molecular model for ammonia. Mol. Phys. 2008, 10, 1039-1046.

[40]. Ungerer, P.; Beauvais, C. ;Delhommelle, J.; Boutin, A.; Rousseau, B.; Fuchs, A. H. Optimization of the anisotropic united atoms intermolecular potential for n-alkanes $J$. Chem. Phys. 2000, 112, 5499-5510.

[41]. Ahunbay, M. G.; Perez-Pellitero, J.; Contreras-Camacho, R. O.; Teuler, J. M.; Ungerer, P.; Mackie, A. D.; Lachet, V. Optimized Intermolecular Potential for Aromatic Hydrocarbons Based on Anisotropic United Atoms. III. Polyaromatic and Naphthenoaromatic Hydrocarbons. J. Phys. Chem. B 2005, 109 , 2970-2976 
[42]. Ferrando, N.; Lachet, V.; Teuler, J. M.; Boutin, A. Transferable Force Field for Alcohols and Polyalcohols. J. Phys. Chem. B 2009, 113, 5985-5995.

[43]. Ferrando, N.; Lachet, V.; Perez-Pellitero, J.; Mackie, A. D.; Malfreyt, P.; Boutin, A. A Transferable Force Field to Predict Phase Equilibria and Surface Tension of Ethers and Glycol Ethers. J. Phys. Chem. B 2011,115, 10654-10664.

[44]. Kong, C.L. Combining rules for intermolecular potential parameters. II. Rules for the Lennard-Jones (12-6) potential and the Morse potential J. Phys. Chem. 1973, 59 (5) 2464-2467.

[45]. Panagiotopoulos, A. Z. Direct determination of phase coexistence properties of fluids by Monte Carlo simulation in a new ensemble Mol. Phys. 1987, 61, 813-826.

[46]. Allen, M. P.; Tildesley, D. J. Computer Simulation of Liquids, Oxford University Press, New-York, 1987.

[47]. Frenkel, D.; Smit, B. Understanding Molecular Simulation: From Algorithms to Applications, Academic Press, San Diego, 1996.

[48]. Mackie, A. D.; Tavitian, B.; Boutin, A.; Fuchs, A. H. Vapour-Liquid Phase Equilibria Predictions of Methane-Alkane Mixtures by Monte Carlo Simulation Mol. Sim. 1997, 115.

[49]. Ungerer, P.; Tavitian, B.; Boutin, A. Applications of Molecular Simulation in the Oil and Gas Industry, $1^{\text {st }}$ Ed.; Edition Technip:Rueil-Malmaison, France, 2005.

[50]. Panagiotopoulos A.Z.; Quirke, N.; Stapleton, M.; Tildesley, D.J. Phase equilibria by simulation in the Gibbs ensemble. Mol. Phys. 1988, 63, 527-545.

[51]. Brune, B. J.; Koehler, J. A.; Smith, P. J.; Payne, G. F. Correlation between Adsorption and Small Molecule Hydrogen Bonding. Langmuir 1999, 15, 3987-3992.

[52]. Varfolomeev, M. A., Abaidullina, D. I.; Solomonov, B. N.; Verevkin, S. P.; Emel'yanenko, V. N. Pairwise Substitution Effects, Inter- and Intramolecular Hydrogen Bonds in Methoxyphenols and Dimethoxybenzenes. Thermochemistry, Calorimetry, and First-Principles Calculations. J. Phys. Chem. B 2010, 114, 16503-16516.

[53]. Perez, D. S.; Ruggiero, R.; Morais, L. C.; Machado, A. E. H.; Mazeau, K. Theoretical and Experimental Studies on the Adsorption of Aromatic Compounds onto Cellulose. Langmuir 2004, 20, 3151 - 3158.

[54]. Matos, M. A. R.; Miranda, M. S.; Morais, V. M. F. Thermochemical Study of the Methoxy- and Dimethoxyphenol Isomers. J. Chem. Eng. Data 2003, 48, 669-679.

[55]. Zheng, J.; Kwak, K.; Chen, X.; Asbury, J. B., Fayer, M. D. Formation and Dissociation of Intra-Intermolecular Hydrogen-Bonded Solute-Solvent Complexes: 
Chemical Exchange Two-Dimensional Infrared Vibrational Echo. Spectroscopy. J. Am. Chem. Soc. 2006, 128, 2977-2987.

[56]. Dorofeeva, O. V.; Shishkov, I. F.; Karasev, N. M.; Vilkov, L. V.; Oberhammer, H. Molecular structures of 2-methoxyphenol and 1,2-dimethoxybenzene as studied by gasphase electron diffraction and quantum chemical calculations. J Mol Struct 2009, 933, $132-141$.

[57]. de Heer, M. I.; Korth, H. G.; Mulder, P. Poly Methoxy Phenols in Solution: O-H Bond Dissociation Enthalpies, Structures, and Hydrogen Bonding. J. Org. Chem. 1999, 64, 6969-6975.

[58]. Jorgensen, W. L. Optimized intermolecular potential functions for liquid alcohols. $J$. Phys. Chem. 1986, 90, 1276-1284.

[59]. Chen, B.; Potoff, J. J.; Siepmann, I. J. Monte Carlo Calculations for Alcohols and Their Mixtures with Alkanes. Transferable Potentials for Phase Equilibria. 5. UnitedAtom Description of Primary, Secondary, and Tertiary Alcohols. J. Phys. Chem. B 2001, 105, 3093-3104.

[60]. Rowley, J. R.; Wilding, W. V.; Oscarson, J. L.; Yang, Y.; Giles, N.F. Design Institute for Physical Properties Data (DIPPR-AIChE). 2011.

[61]. Hahn, J., Moerke, K. Determination of the VLE in the systems water - guaiacol and butyl acetate - guaiacol, FIZ report, from Detherm, 1986.

[62]. Balina, T. K.; Krupatkin, I. L., Kalininskij Gosudarstvennyj Universite, Investigation of the hydrazine - guaicol - water system. 1974, 100-104.

[63]. Ksiazczak, A.; Kosinski, J. J. Liquid-Liquid Equilibrium in Binary Polar Aromatic + Hydrocarbon Systems. Fluid Phase Equilib. 1990, 59, 291-308.

[64]. Weissenberger,G.; Henke,R.; Bregmann,L. On the Knowledge of Aromatic Molecular Compounds. XVI. Bivalent Phenols and Their Ethers. Sitzungsber. Oesterr. Akad. Wiss. math. Naturwiss 1925, 134, 471-482.

[65]. Li, H.; Xia, S.; Wu, M.; Ma, P. Isobaric (vapour + liquid) equilibria of binary systems containing butyl acetate for the separation of methoxy aromatic compounds (anisole and guaiacol) from biomass fast pyrolysis oil. J. Chem. Thermodynamics 2015, 87, 141-146.

[66]. Raeissi, S.; Peters, C. J. Application of double retrograde vaporization as an optimizing factor in supercritical fluid separations. J. Supercrit. Fluids 2005, 33, 115120.

[67]. Lee, C. A.; Tang, M.; Ho, S. L.; Chen, Y. P. Solubilities of chlormezanone, metaxalone and methocarbamol in supercritical carbon dioxide. J. Supercrit. Fluids, 85, 
2014, 11-16.

[68]. Leitão, C. M. C. S.; Prado, G. H. C.; Veggi, P. C.; Meireles, M.A.A.; Pereira, C. G. Anacardium occidentale L. leaves extraction via SFE: Global yields, extraction. kinetics, mathematical modeling and economic evaluation. J. Supercrit. Fluids 2013, 78, , 114 123.

[69]. Pereira, C. G.; Marques, M. O. M.; Barreto, A. S.; Siani, A. C.; Fernandes, E. C.; Meireles, M. A. A. Extraction of indole alkaloids from Tabernaemontana catharinensis using supercritical $\mathrm{CO}_{2}$ +ethanol: an evaluation of the process variables and the raw material origin. J. Supercrit. Fluids 2004, 30, 51-61.

[70]. Wolbach, J. P.; Sandler, S. I. Using molecular orbital calculations to describe the phase behavior of cross-associating mixtures. Ind. Eng. Chem. Res. 1998, 37, 2917-2928.

[71]. Pereira, C. G.; Grandjean, L.; Betoulle, S.; Ferrando, N.; Fejean, C.; Lugo, R.; de Hemptinne, J.C.; Mougin, P. Fluid Phase Equilib. 2014, 382, 219-234.

[72]. Trinh, T. K. H.; de Hemptinne, J. C.; Lugo, R.; Ferrando, N.; Passarello, J.P. J. Chem. Eng. Data 2016, 61, 19-34.

\section{$\underline{\text { Figure Captions }}$}

Figure 1: Conformational isomers of guaiacol [56].

Figure 2: Intermolecular radial distribution function $\mathrm{O}(\mathrm{H})-\mathrm{O}(\mathrm{H})$ (solid line) and $\mathrm{O}(\mathrm{H})-\mathrm{O}$ (dashed line) in liquid guaiacol at $323.15 \mathrm{~K}, 0.1 \mathrm{MPa}$.

Figure 3: Intermolecular histogram O-H in liquid guaiacol at $323 \mathrm{~K}, 0.1 \mathrm{MPa}$.

Figure 4: Association schemes of for guaiacol.

Figure 5: Comparison of vapor pressure data of guaiacol from literature [60] and calculated using Molecular Simulation ( $\square$ ) and GC-PPC-SAFT using Scheme $1(\Delta)$ and Scheme $2(\circ)$.

Figure 6: Comparison of liquid volume data of guaiacol from literature [60] and results using Molecular Simulation ( $\square$ ) and GC-PPC-SAFT using Scheme $1(\Delta)$ and Scheme $2(\circ)$. 
Figure 7: Comparison of vaporization enthalpy data of guaiacol from literature [60] and results using Molecular Simulation ( $\square$ ) and GC-PPC-SAFT using Scheme $1(\Delta)$ and Scheme 2 $(0)$.

Figure 8: Phase diagram of the system water + guaiacol at 313.6, 334.4, 353.9 and $372 \mathrm{~K}$ using GC-PPC-SAFT with the two guaiacol schemes. Experimental data from [61].

Figure 9: Guaiacol + water liquid-liquid phase equilibrium at $0.1 \mathrm{MPa}$, using GC-PPC-SAFT with the Scheme 1 in the predictions (solid line). The use of Scheme 2 didn't reveal any liquid-liquid phase split. Experimental data (*) from [62] .

Figure 10: Phase diagram n-hexadecane + guaiacol system at 0.1 MPa, using GC-PPC-SAFT with the two guaiacol schemes. Experimental data from [63].

Figure 11: Phase diagram of the system ethanol + guaiacol at 290.15 K using GC-PPC-SAFT with the two guaiacol schemes. Experimental data from [64].

Figure 12: Phase diagram of the system octanol + guaiacol at 433.15, 448.15 and $463.15 \mathrm{~K}$ using GC-PPC-SAFT with the two guaiacol schemes. Experimental data from [8].

Figure 13: Bubble pressure of the guaiacol + acetone binary system at $290.15 \mathrm{~K}$ using GCPPC-SAFT with the two guaiacol schemes. Experimental data from [64]. Ideal mixture assumption between the extrapolated vapor pressures of the two pure components.

Figure 14: Phase behavior description of the butyl-acetate + guaiacol binary system at 101.3 $\mathrm{kPa}$ using GC-PPC-SAFT with the two guaiacol schemes. Experimental data from [65].

Figure 15: Phase diagram of the system methane + guaiacol 443.15 K using GC-PPC-SAFT with the two guaiacol schemes and Molecular Simulation. Experimental data (this work, Table 6).

Figure 16: Phase diagram of the system $\mathrm{CO}_{2}+$ guaiacol at $393.15 \mathrm{~K}$ using GC-PPC-SAFT with the two guaiacol schemes and Molecular Simulation. Experimental data from [7]. 
Figure 17: Cross-over behavior for the $\mathrm{CO}_{2}+$ guaiacol system using predicted values from GC-PPC-SAFT, using Scheme 1.

Figure 18: Phase diagram of the system $\mathrm{H}_{2} \mathrm{~S}+$ guaiacol at $373.15 \mathrm{~K}$ and $573.15 \mathrm{~K}$ using GCPPC-SAFT (Scheme 1) and Molecular Simulation.

Figure 19: Phase diagram of the system $\mathrm{NH}_{3}+$ guaiacol at $373.15 \mathrm{~K}$ and $573.15 \mathrm{~K}$ using GCPPC-SAFT (Scheme 1) and Molecular Simulation.

Figure 20: Phase diagram of the system $\mathrm{H}_{2}+$ guaiacol at $573.15 \mathrm{~K}$ using GC-PPC-SAFT (Scheme 1) and Molecular Simulation.

Figure 21: Phase diagram of the system CO + guaiacol at 573.15 K using GC-PPC-SAFT (Scheme 1) and Molecular Simulation.

Figure 22: Henry constant of gases in guaiacol. 
Table 1: Parameters of the pure compounds used in GC-PPC-SAFT Equation of State.

\begin{tabular}{llllllllllllll}
\hline Compound & $\boldsymbol{\varepsilon} / \boldsymbol{k}(\boldsymbol{K})$ & $\boldsymbol{\sigma}(\boldsymbol{A})$ & $\boldsymbol{m}$ & $\boldsymbol{\mu}(\boldsymbol{D})$ & $\boldsymbol{x}_{p}{ }^{\mu} \boldsymbol{m}$ & $\boldsymbol{Q}(\boldsymbol{B})$ & $\boldsymbol{x}_{\boldsymbol{p}}{ } \boldsymbol{m}$ & $\begin{array}{l}\text { association } \\
\text { scheme }\left({ }^{*}\right)\end{array}$ & $\varepsilon^{A B} / \boldsymbol{k}(\boldsymbol{K})$ & $\boldsymbol{\kappa}^{A B}$ & $J(\boldsymbol{e V})$ & $\boldsymbol{R e f}$ \\
\hline $\mathrm{CH}_{4}$ & 147.42 & 3.6582 & 1.0334 & - & - & - & - & 0 & - & - & 12.6 & {$[15]$} \\
$\mathrm{CO}_{2}$ & 139.99 & 2.9839 & 1.8465 & - & - & 4.3 & 0.527 & $(--)$ & 449.71 & 0.0947 & 13.8 & {$[15]$} \\
$\mathrm{C}_{2} \mathrm{H}_{6} \mathrm{O}$ & 191.63 & 2.9178 & 3.0722 & 1.7 & 0.2 & - & - & $(-+)$ & 2125.52 & 0.0940 & 12.8 & {$[26]$} \\
$\mathrm{H}_{2} \mathrm{O}$ & 218.79 & 3.3845 & 0.8096 & 1.85 & 0.295 & - & - & $(--++)$ & 1813.0 & 0.0356 & 10 & {$[27]$} \\
$\mathrm{H}_{2}$ & 26.63 & 2.9060 & 1.1120 & - & - & - & - & 0 & - & - & 15 & {$[15]$} \\
$\mathrm{H}_{2} \mathrm{~S}$ & 225.05 & 3.4161 & 1.3018 & - & - & - & - & $(-++)$ & 449.71 & 0.0947 & 10.45 & {$[17]$} \\
$\mathrm{CO}$ & 95.25 & 3.3979 & 1.17 & - & - & - & - & 0 & - & - & 18 & {$[28]$} \\
$\mathrm{NH}_{3}$ & 204.63 & 3.2386 & 1.1157 & 1.469 & 1.3976 & - & - & $(-+++)$ & 646.38 & 0.00597 & 0 & {$[29]$}
\end{tabular}

$(*)$ : the association scheme shows the number of electron-donor (-) and electron acceptor $(+)$ sites attributed to each group. ' 0 ' means no sites. 
Table 2: Group Parameters of GC-PPC-SAFT Equation of State.

\begin{tabular}{|c|c|c|c|c|c|c|c|c|c|c|c|}
\hline Group & $\varepsilon / k(K)$ & $\sigma(\AA)$ & $\mu(D)$ & $x_{p}^{\mu} m$ & $Q(B)$ & $x_{p}{ }^{Q} m$ & $\begin{array}{l}\text { Association } \\
\text { Scheme }(* *)\end{array}$ & $\varepsilon^{A B} / k(K)$ & $\boldsymbol{\kappa}^{A B}$ & $R_{I}$ & $\operatorname{Ref}$ \\
\hline$\left(\mathrm{CH}_{3}\right)$ & 189.96 & 3.4873 & - & - & - & - & 0 & - & - & 0.7866 & [30] \\
\hline$\left(\mathrm{CH}_{2}\right)$ & 261.09 & 3.9308 & - & - & - & - & 0 & - & - & 0.3821 & [30] \\
\hline$(\mathrm{CH})_{\mathrm{BR}}$ & 294.22 & 3.7572 & - & - & - & - & 0 & - & - & 0.3805 & [17] \\
\hline$(\mathrm{C})_{\mathrm{AB}}$ & 391.54 & 4.2783 & - & - & - & - & 0 & - & - & 0.00156 & [17] \\
\hline$(\mathrm{C}=\mathrm{O})$ & 480.73 & 3.7495 & 2.7 & 0.57 & & & $(-)$ & 2143.3 & 0.00885 & 0.64373 & [31] \\
\hline$(\mathrm{COO})$ & 362.82 & 3.3447 & $(*)$ & 1.15 & & & $(-)$ & 2143.3 & 0.00885 & 0.82737 & {$[32]$} \\
\hline$(\mathrm{OH})_{\text {linear alcohols }}$ & 307.51 & 2.8138 & 1.7 & 0.5 & - & - & $(-+)$ & 2143.3 & 0.00885 & 0.8318 & [13] \\
\hline$(\mathrm{OH})_{\text {guaiacol }}$ & 307.51 & 2.8138 & 1.22 & 0.5 & - & - & $(-+)$ & 2285.17 & 0.0052 & 0.2445 & [33] \\
\hline$(\mathrm{OH})_{\text {guaiacol }}$ & 307.51 & 2.8138 & 1.22 & 0.5 & - & - & $(-+)$ & 1549.4 & 0.00898 & 1.0308 & [10] \\
\hline$(-\mathrm{O}-)_{\text {guaiacol }}$ & 280.96 & 3.5764 & 1.22 & 1.2 & - & - & $(-)$ & 2285.17 & 0.0052 & 0.4516 & [32] \\
\hline Guaiacol ring & - & - & - & - & 8.5 & 0.25 & $(-)$ & 1323.01 & 0.0052 & - & [32] \\
\hline Guaiacol ring & - & - & - & - & 8.5 & 0.25 & $(-)$ & 1000 & 0.0198 & - & [10] \\
\hline
\end{tabular}

(*) See original paper for details.

(**) the association scheme shows the number of electron-donor (-) and electron acceptor $(+)$ sites attributed to each group. ' 0 ' means no sites. 
Table 3: Molecular model for small gases [34] - [39].

\begin{tabular}{|c|c|c|c|c|c|c|c|}
\hline \multirow[t]{2}{*}{ Molecule } & \multirow{2}{*}{$\begin{array}{l}\text { Center of } \\
\text { force }\end{array}$} & \multicolumn{3}{|c|}{ Position } & \multicolumn{2}{|c|}{$\begin{array}{l}\text { Lennard-Jones } \\
\text { Parameters }\end{array}$} & \multirow{2}{*}{$\begin{array}{l}\text { Charge } \\
\text { (e) }\end{array}$} \\
\hline & & $X$ & Y & $\mathrm{Z}$ & $\varepsilon / \mathrm{k}(\mathrm{K})$ & $\sigma(\AA)$ & \\
\hline $\mathrm{CH}_{4}$ & $\mathrm{CH}_{4}$ & 0 & 0 & 0 & 149.920 & 3.7327 & 0 \\
\hline \multirow{3}{*}{$\mathrm{CO}_{2}$} & $\mathrm{C}$ & 0 & 0 & 0 & 28.129 & 2.7570 & 0.6512 \\
\hline & $\mathrm{O} 1$ & 1.149 & 0 & 0 & 80.507 & 3.0330 & -0.3256 \\
\hline & $\mathrm{O} 2$ & -1.149 & 0 & 0 & 80.507 & 3.0330 & -0.3256 \\
\hline \multirow{4}{*}{$\mathrm{H}_{2}$} & $\mathrm{H}_{2}$ & 0 & 0 & 0 & 36.700 & 2.9600 & \\
\hline & q- & 0 & 0 & 0 & - & - & -0.9328 \\
\hline & $q+(1)$ & 0.3705 & 0 & 0 & - & - & 0.4664 \\
\hline & $q+(2)$ & -0.3705 & 0 & 0 & - & - & 0.4664 \\
\hline \multirow{2}{*}{$\mathrm{CO}$} & C & 0 & 0 & 0 & 47.676 & 3.2490 & 0.05376 \\
\hline & $\mathrm{O}$ & 1.1283 & 0 & 0 & 30.820 & 3.4052 & -0.05376 \\
\hline \multirow{4}{*}{$\mathrm{H}_{2} \mathrm{~S}$} & S & 0 & 0 & 0 & 250.000 & 3.7300 & 0.4000 \\
\hline & H1 & 0.9639 & 0.9308 & 0 & - & - & 0.2500 \\
\hline & $\mathrm{H} 2$ & -0.9639 & -0.9308 & 0 & - & - & 0.2500 \\
\hline & q- & 0 & 0.1862 & 0 & - & - & -0.9000 \\
\hline \multirow{4}{*}{$\mathrm{NH}_{3}$} & $\mathrm{~N}$ & 0 & 0 & 0.0757 & 182.900 & 3.3760 & -0.9993 \\
\hline & H1 & 0.9347 & 0 & -0.3164 & - & - & 0.3331 \\
\hline & $\mathrm{H} 2$ & -0.4673 & 0.8095 & -0.3164 & - & - & 0.3331 \\
\hline & $\mathrm{H} 3$ & -0.4673 & -0.8095 & -0.3164 & - & - & 0.3331 \\
\hline
\end{tabular}


Table 4: Non-bonded parameters of the AUA4 force field for guaiacol.

\begin{tabular}{lcccc}
\hline $\begin{array}{l}\text { Center of } \\
\text { force }\end{array}$ & $\varepsilon / k(\mathrm{~K})$ & $\sigma(\AA)$ & $\delta(\AA)$ & Charge (e) \\
\hline $\mathrm{CH}_{3}$ & 120.15 & 3.607 & 0.216 & +0.223 \\
$\mathrm{CH}_{\text {arom }}$ & 89.4 & 3.246 & 0.407 & 0 \\
$\mathrm{C}_{\text {arom }}(-\mathrm{OH})$ & 37.7 & 3.246 & 0 & +0.265 \\
$\mathrm{C}_{\text {arom }}(-\mathrm{O})$ & 37.7 & 3.246 & 0 & +0.223 \\
$\mathrm{O}\left(-\mathrm{CH}_{3}\right)$ & 59.69 & 2.991 & 0 & -0.446 \\
$\mathrm{O}(\mathrm{OH})$ & 125.01 & 3.081 & 0.010 & -0.700 \\
$\mathrm{H}(\mathrm{OH})$ & 0 & 0 & 0 & +0.435 \\
\hline
\end{tabular}


Table 5: Bonded parameters of the AUA4 force field for guaiacol.

\begin{tabular}{|c|c|c|c|c|}
\hline \multirow{3}{*}{ Groups } & \multicolumn{4}{|c|}{ Parameter } \\
\hline & \multirow{2}{*}{$\begin{array}{c}\text { Bond } \\
\text { lenght } r_{0} \\
(\AA)\end{array}$} & \multicolumn{2}{|c|}{ Angle } & \multirow{2}{*}{$\begin{array}{l}\text { Torsion } \\
a_{i}(\mathrm{~K})\end{array}$} \\
\hline & & $\begin{array}{c}\theta_{0} \\
(\mathrm{deg})\end{array}$ & $\begin{array}{c}k_{\text {bending }} \\
(\mathrm{K})\end{array}$ & \\
\hline $\mathrm{CH}_{3}-\mathrm{O}$ & 1.360 & - & - & - \\
\hline $\mathrm{CH}_{\mathrm{x} \text { arom }}=\mathrm{CH}_{\mathrm{x} \text { arom }}(x=0$ or 1$)$ & 1.400 & - & - & - \\
\hline $\mathrm{C}_{\text {arom }}-\mathrm{O}$ & 1.430 & - & - & - \\
\hline $\mathrm{O}-\mathrm{H}$ & 0.945 & - & - & - \\
\hline $\mathrm{CH}_{3}-\mathrm{O}-\mathrm{CH}_{\text {arom }}$ & - & 112 & 69000 & - \\
\hline $\mathrm{CH}_{\mathrm{x} \text { arom }}=\mathrm{CH}_{\mathrm{x} \text { arom }}=\mathrm{CH}_{\mathrm{x} \text { arom }}(x=0$ or 1$)$ & - & 120 & rigid & - \\
\hline $\mathrm{CH}_{\mathrm{x} \text { arom }}=\mathrm{C}_{\text {arom }}-\mathrm{O}(x=0$ ou 1$)$ & - & 120 & rigid & - \\
\hline $\mathrm{C}_{\text {arom }}-\mathrm{O}-\mathrm{H}$ & - & 108.5 & 61000 & - \\
\hline $\mathrm{CH}_{\mathrm{x} \text { arom }}-\mathrm{CH}_{\mathrm{x} \text { arom }}-\mathrm{CH}_{\mathrm{x} \text { arom }}-\mathrm{CH}_{\mathrm{x} \text {-arom }}(x=0$ or 1$)$ & - & - & - & rigid \\
\hline $\mathrm{CH}_{\mathrm{x} \text { arom }}-\mathrm{CH}_{\mathrm{x} \text { arom }}-\mathrm{CH}_{\mathrm{x} \text { arom }}-\mathrm{O}(x=0$ ou 1$)$ & - & - & - & rigid \\
\hline $\mathrm{CH}_{\mathrm{x} \text { arom }}-\mathrm{CH}_{\mathrm{x} \text { arom }}-\mathrm{O}-\mathrm{H}$ & - & - & - & $\begin{array}{c}\mathrm{a}_{0}=845.65 ; \mathrm{a}_{1}=0 ; \\
\mathrm{a}_{2}=-845.65 ; \mathrm{a}_{3}=0\end{array}$ \\
\hline $\mathrm{O}-\mathrm{CH}_{\mathrm{x} \text { arom }}-\mathrm{CH}_{\mathrm{x} \text { arom }}-\mathrm{CH}_{\mathrm{x} \text { arom }}$ & - & - & - & rigid \\
\hline $\mathrm{O}-\mathrm{C}_{\mathrm{arom}}-\mathrm{C}_{\mathrm{arom}}-\mathrm{O}$ & - & - & - & rigid \\
\hline $\mathrm{CH}_{\text {arom }}-\mathrm{CH}_{\text {arom }}-\mathrm{O}-\mathrm{CH}_{3}$ & - & - & - & $\begin{array}{c}\mathrm{a}_{0}=1631.27 ; \mathrm{a}_{1}=2651.77 ; \\
\mathrm{a}_{2}=868.86 ; \mathrm{a}_{3}=-2184.14 ; \\
\mathrm{a}_{4}=-3028.37 ; \mathrm{a}_{5}=-3065.12 ; \\
\mathrm{a}_{6}=1926.79 ; \mathrm{a}_{7}=1723.03 ; \\
\mathrm{a}_{8}=-497.96\end{array}$ \\
\hline
\end{tabular}


Table 6: Experimental data of systems methane + guaiacol. Uncertainties (U) on the measurements are as follows: $\mathrm{U}(\mathrm{T})=0.05 \mathrm{~K}, \mathrm{U}(\mathrm{P})=0.05 \mathrm{MPa}, \mathrm{u}\left(\mathrm{x}_{1}\right)=0.002$

\begin{tabular}{cccc}
\hline Systems & $\mathbf{T}(\mathbf{K})$ & $\mathbf{P}(\mathbf{M P a})$ & $\mathbf{x}_{\mathbf{1}}$ \\
\hline Methane (1) + guaiacol (2) & 443.5 & 4.967 & 0.03421 \\
& 443.5 & 9.988 & 0.06633 \\
& 443.5 & 14.874 & 0.10439 \\
& 443.5 & 24.929 & 0.20514 \\
& 443.5 & 34.916 & 0.26742 \\
\hline
\end{tabular}


Table 7: Associative Parameters for guaiacol.

\begin{tabular}{|c|c|c|c|c|}
\hline & \multirow[b]{2}{*}{ Group } & \multicolumn{3}{|c|}{ Parameters } \\
\hline & & $\varepsilon^{A B} / k(K)$ & $\boldsymbol{\kappa}^{A B}$ & $\boldsymbol{R}$ \\
\hline \multirow[t]{2}{*}{ Scheme 1} & $\mathrm{OH}$ & 812.17 & 0.2429 & 0.4040 \\
\hline & $\mathrm{O}$ & 2298.84 & 0.0051 & 0.4516 \\
\hline \multirow[t]{2}{*}{ Scheme 2} & $\mathrm{OH}$ & 534.50 & 0.1466 & 0.4102 \\
\hline & $\mathrm{O}$ & 2303.49 & 0.0050 & 0.4511 \\
\hline
\end{tabular}


Table 8: Results of vapor pressures, density and heat of vaporization of guaiacol obtained from Molecular Simulation.

\begin{tabular}{cccc}
\hline Temperature $(\mathrm{K})$ & Vapor Pressure $(\mathrm{MPa})$ & Density $\left(\mathrm{kg} / \mathrm{m}^{3}\right)$ & Heat of vaporization $(\mathrm{kJ} / \mathrm{mol})$ \\
\hline 450 & 0.051 & 967.3 & 48.6 \\
500 & 0.173 & 922.9 & 45.4 \\
550 & 0.460 & 870.0 & 41.2 \\
600 & 0.986 & 802.3 & 36.3 \\
\hline
\end{tabular}


Table 9: Relative deviations from experimental data for correlated values of vapor pressure, liquid volume and vaporization enthalpy of guaiacol using GC-PPC-SAFT and Molecular Simulation (in \%).

\begin{tabular}{lcccc}
\cline { 2 - 4 } & \multicolumn{2}{c}{ GC-PPC-SAFT } & Molecular Simulation \\
& $\begin{array}{l}\text { Temperature } \\
\text { range (K) }\end{array}$ & Scheme 1 & Scheme 2 & \\
\hline Vapor Pressure & $361-478$ & 2.15 & 2.17 & 4.8 \\
Liquid Volume & $313-478$ & 0.36 & 0.38 & 1.3 \\
$\begin{array}{l}\text { Vaporization } \\
\text { Enthalpy }\end{array}$ & $305-627$ & 4.5 & 4.5 & 4.8 \\
\hline
\end{tabular}


Table 10: Relative deviations of the solubility for systems with guaiacol.

\begin{tabular}{|c|c|c|c|c|c|}
\hline \multirow{3}{*}{ System } & \multicolumn{5}{|c|}{ Relative Deviation $(\%)^{\mathrm{a}}$} \\
\hline & \multirow[t]{2}{*}{ Temperature (K) } & \multicolumn{2}{|c|}{ GC-PPC-SAFT } & \multirow{2}{*}{$\begin{array}{l}\text { Molecular } \\
\text { Simulation }\end{array}$} & \multirow[t]{2}{*}{ Ref } \\
\hline & & Scheme 1 & Scheme 2 & & \\
\hline \multirow[t]{3}{*}{$\mathrm{CO}_{2}+$ guaiacol } & 323.15 & 11.9 & 10.4 & - & [7] \\
\hline & 353.15 & 12.5 & 9.4 & - & \\
\hline & 393.15 & 10.3 & 4.7 & 56.4 & \\
\hline Methane + guaiacol & 443.15 & 20.2 & 19.5 & - & This work \\
\hline Ethanol + guaiacol & 290.15 & $6.2\left(\right.$ or $\left.2.5^{\mathrm{b}}\right)$ & $9.1\left(\right.$ or $\left.7.1^{\mathrm{b}}\right)$ & - & [64] \\
\hline \multirow[t]{3}{*}{ Octanol + guaiacol } & 433.15 & 1.7 & 3.2 & - & [8] \\
\hline & 488.15 & 1.3 & 3.7 & - & \\
\hline & 463.15 & 0.6 & 2.4 & - & \\
\hline Acetone + guaiacol & 290.15 & $50^{c}$ & $71^{\mathrm{c}}$ & - & {$[64]$} \\
\hline Butyl acetate + guaiacol & $(401.2-473.5)^{\mathrm{d}}$ & 26 & 36 & - & [65] \\
\hline \multirow[t]{4}{*}{ Water + guaiacol } & 313.6 & 7.8 & $>100$ & - & {$[61]$} \\
\hline & 334.4 & 12.0 & $>100$ & - & \\
\hline & 353.9 & 18.0 & $>100$ & - & \\
\hline & 372.0 & 17.6 & $>100$ & - & \\
\hline
\end{tabular}

${ }^{\text {a }}$ Relative Deviation $(\%)=\left(\frac{1}{n} \sum_{i}^{n}\left|\frac{x_{i}^{\text {cal }}-x_{i}^{\exp }}{x_{i}^{\text {exp }}}\right|\right) \times 100$, where $x_{i}$ is the molar liquid fraction of the solvent

(1), except for (c), ${ }^{\mathrm{b}}$ Disregarding the value at $1.9 \times 10^{-3} \mathrm{MPa},{ }^{\mathrm{c}}$ relative deviation expressed in bubble pressure $\left(\frac{1}{n} \sum_{i}^{n}\left|\frac{P_{i}^{c a l}-P_{i}^{\exp }}{P_{i}^{\exp }}\right|\right) \times 100,{ }^{\mathrm{d}}$ experimental data at isobaric conditions (101.3 kPa). 


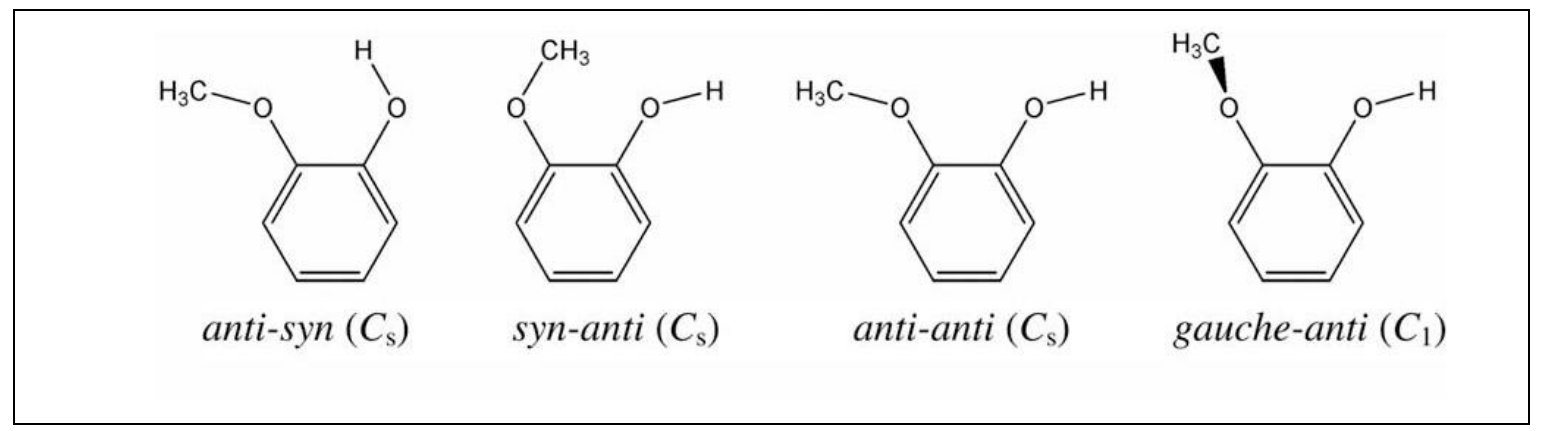

Figure 1. 


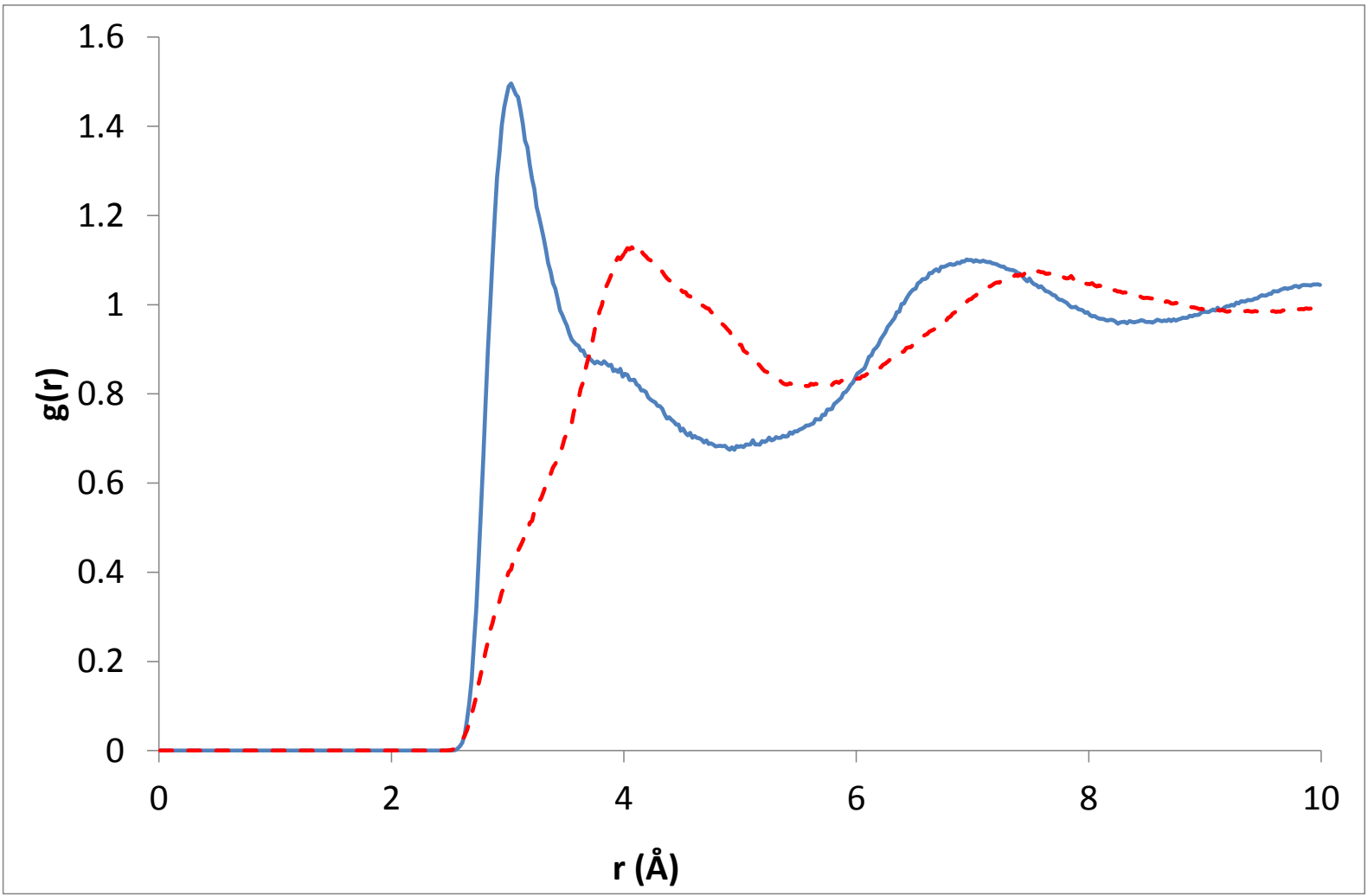

Figure 2. 


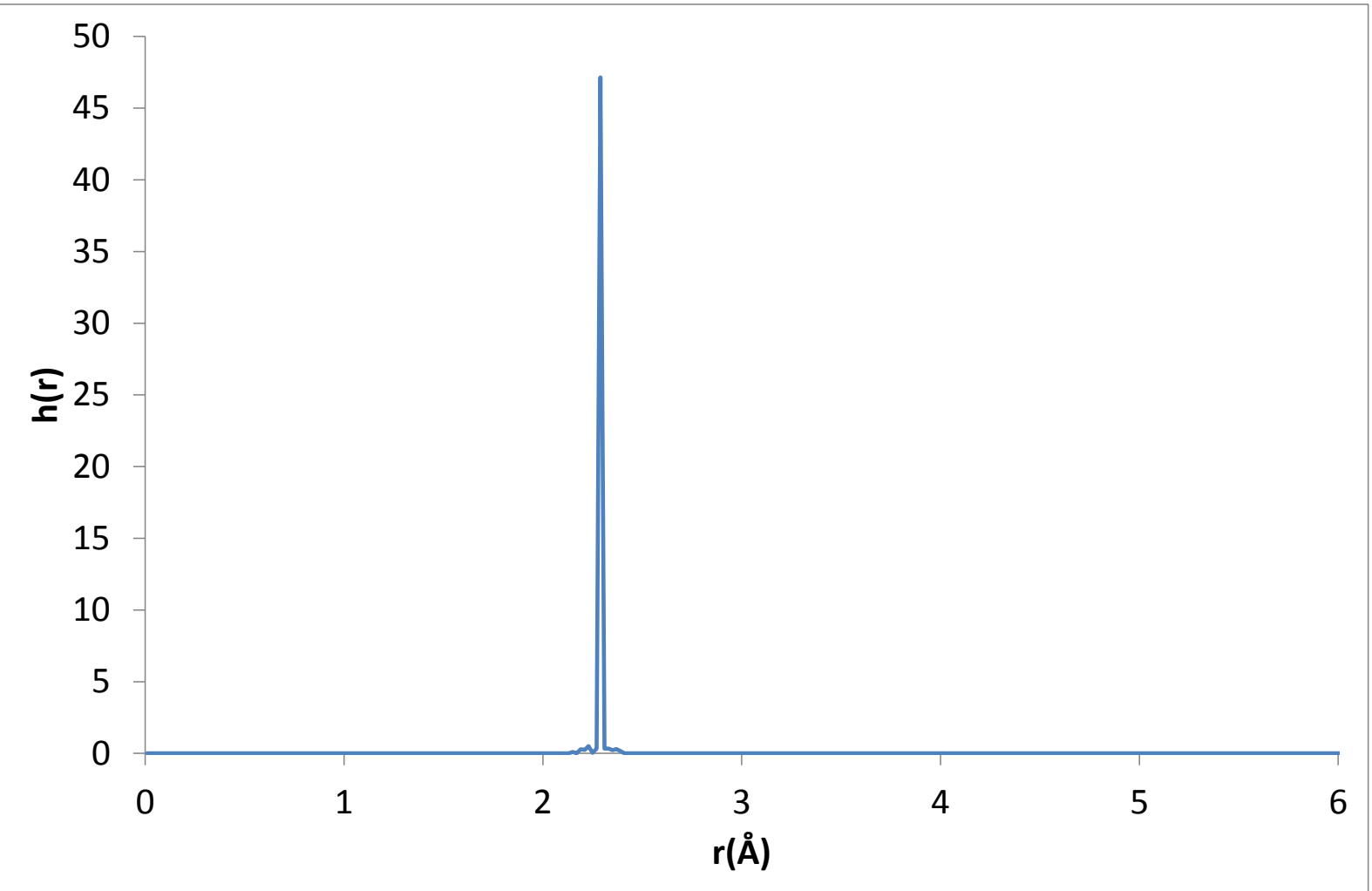

Figure 3. 


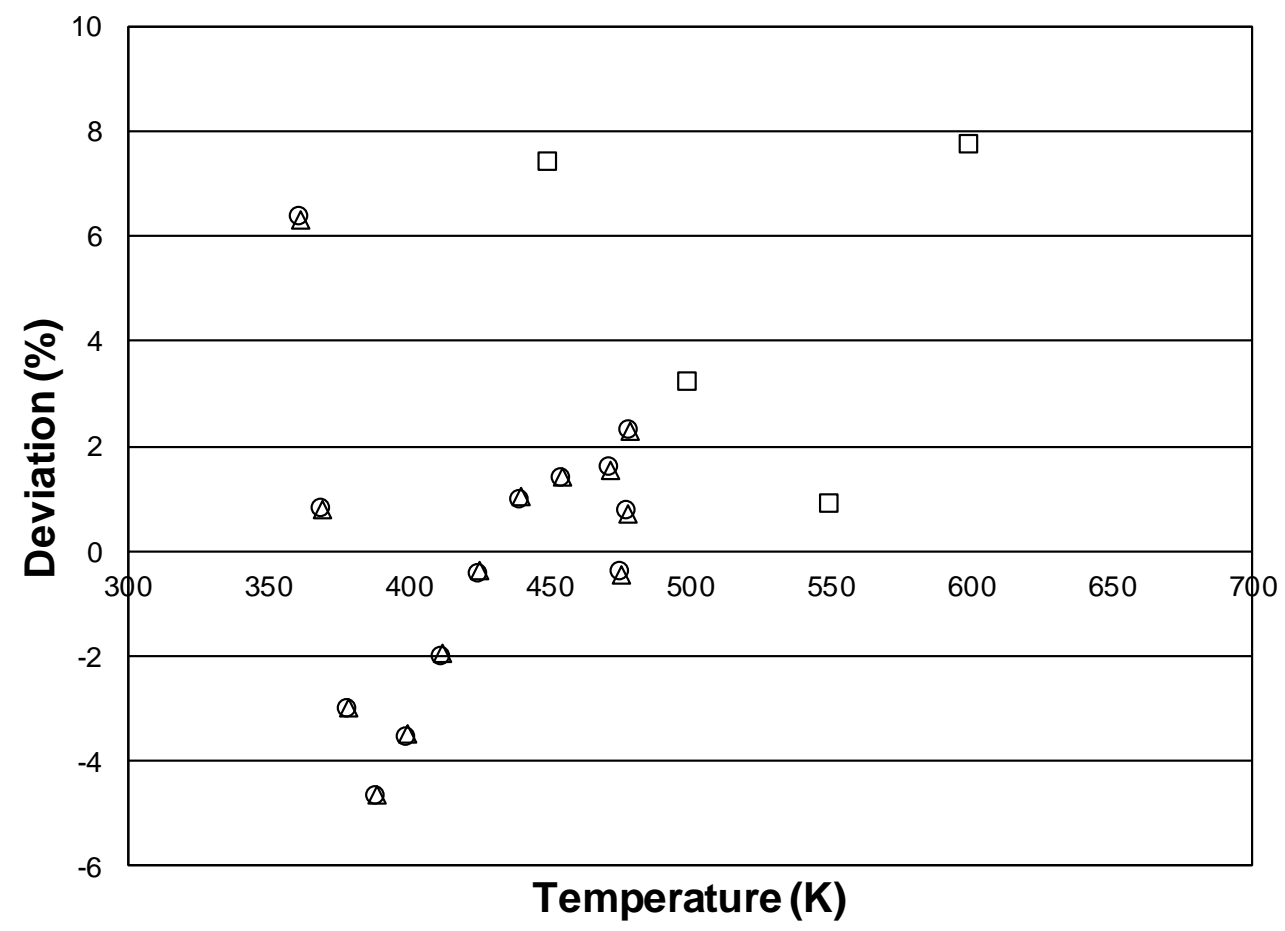

Figure 5. 


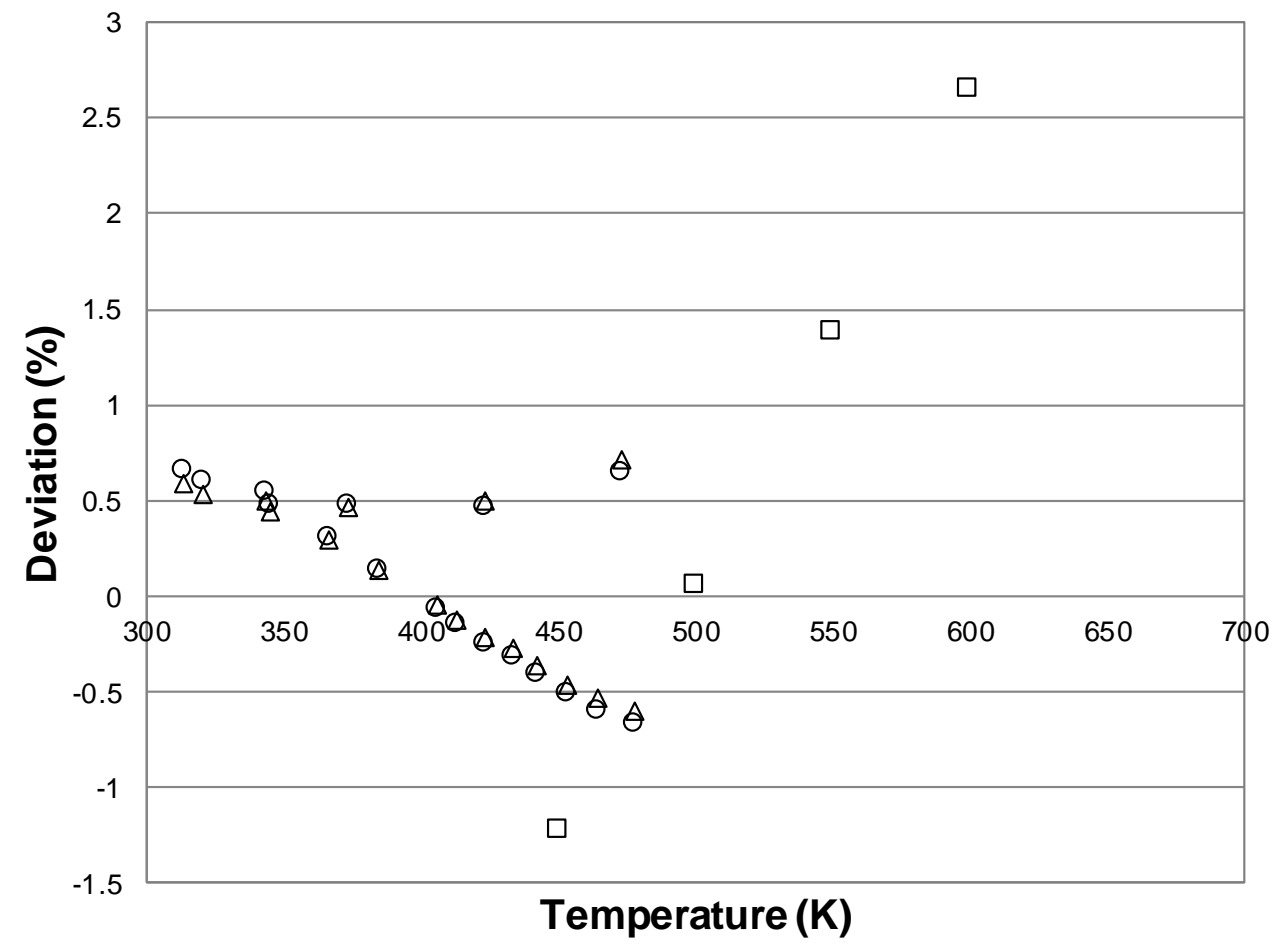

Figure 6. 


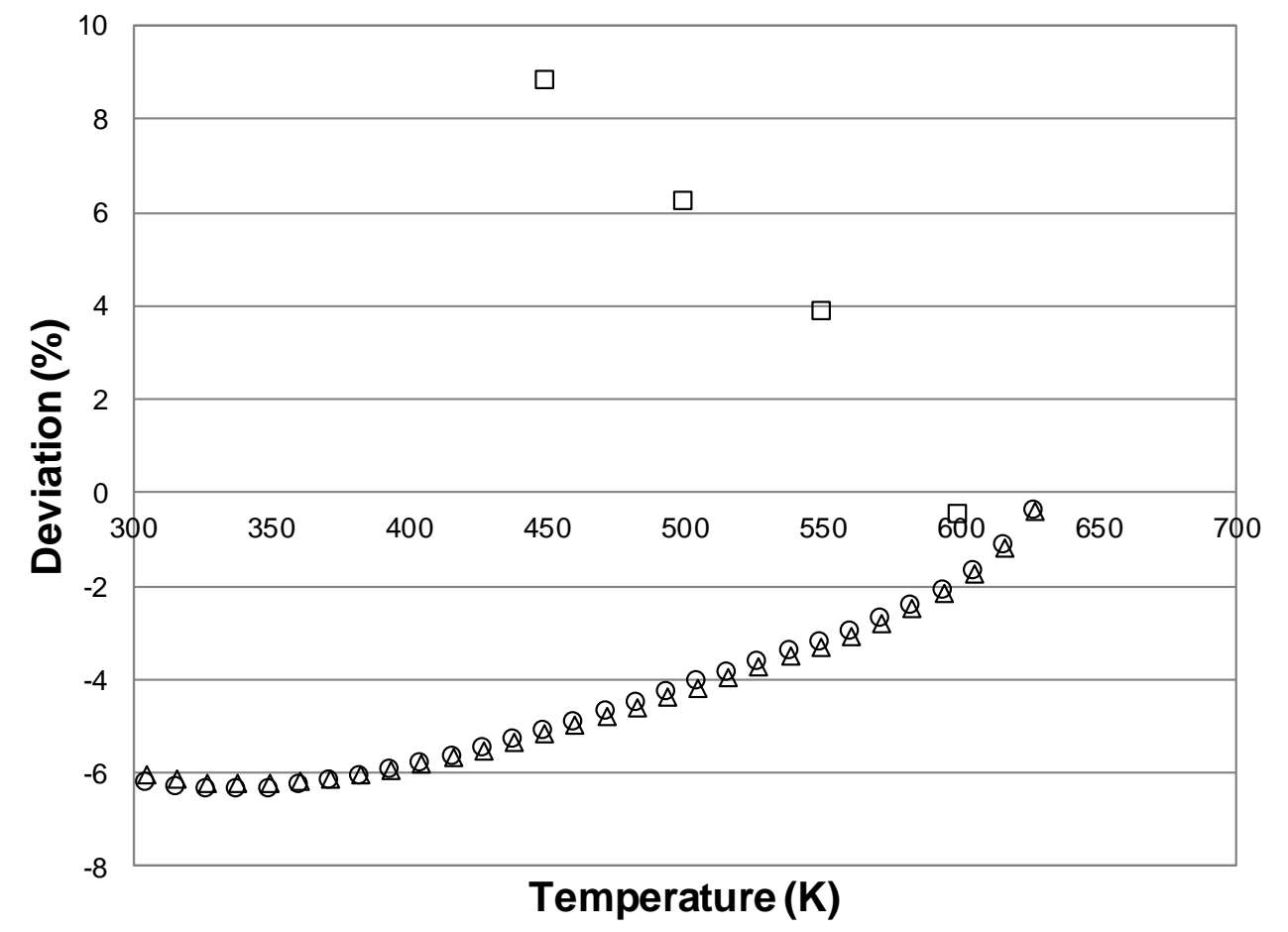

Figure 7 . 


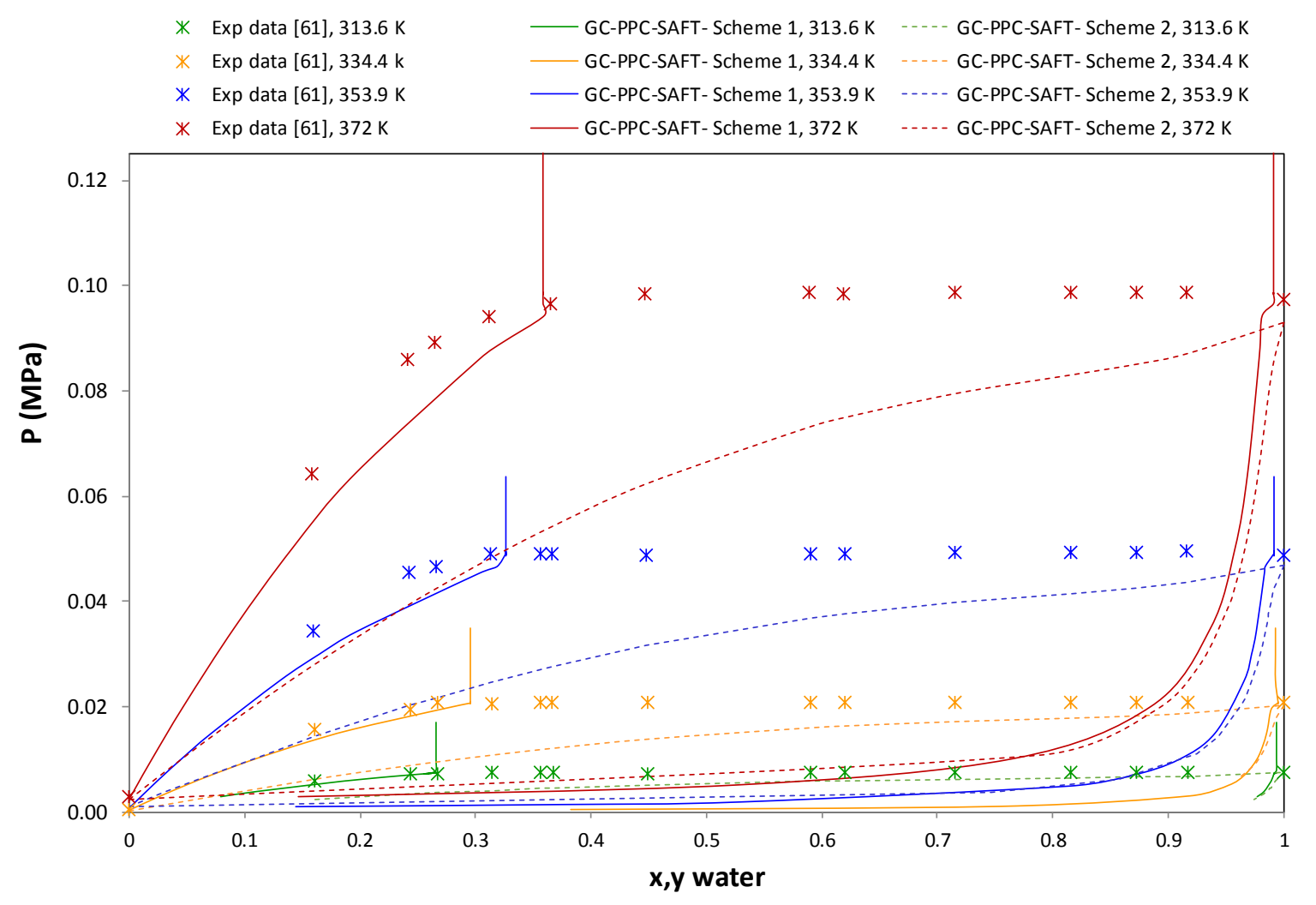

Figure 8. 


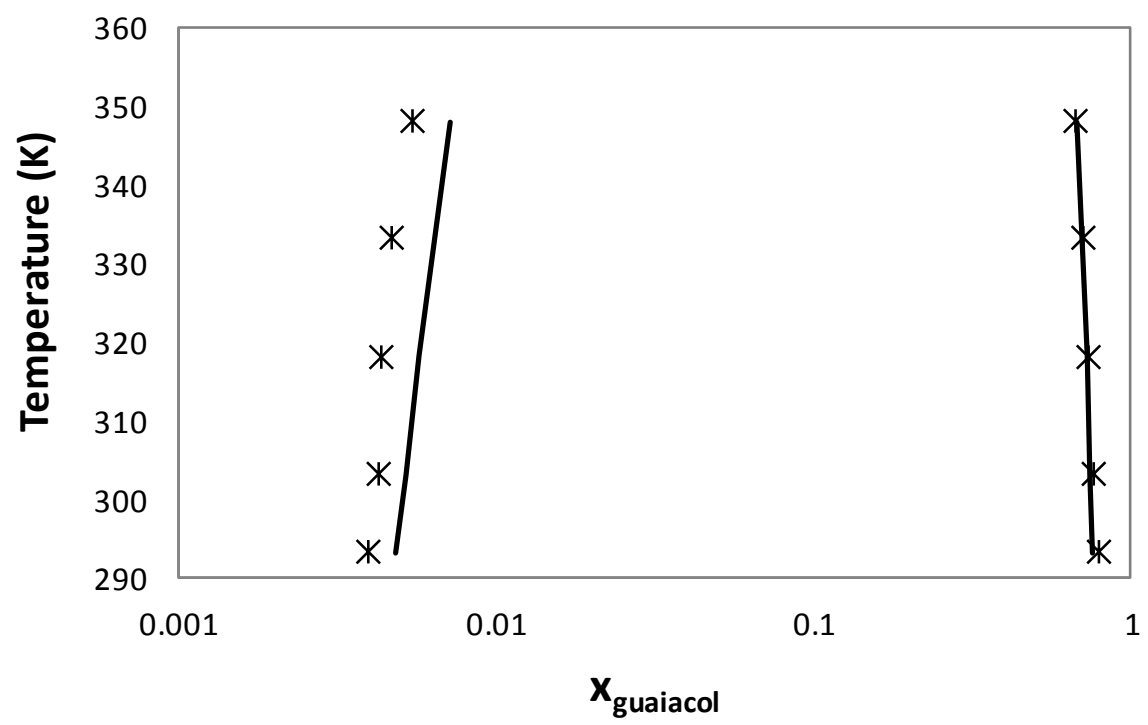

Figure 9. 


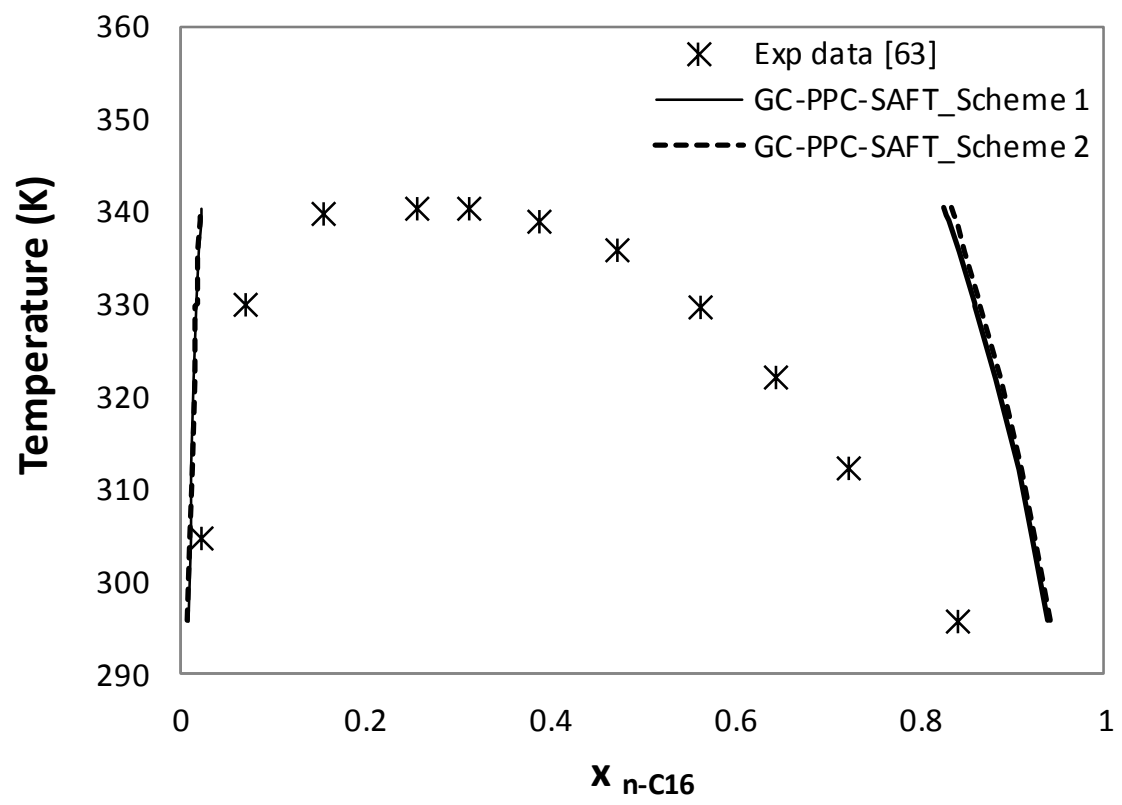

Figure 10. 


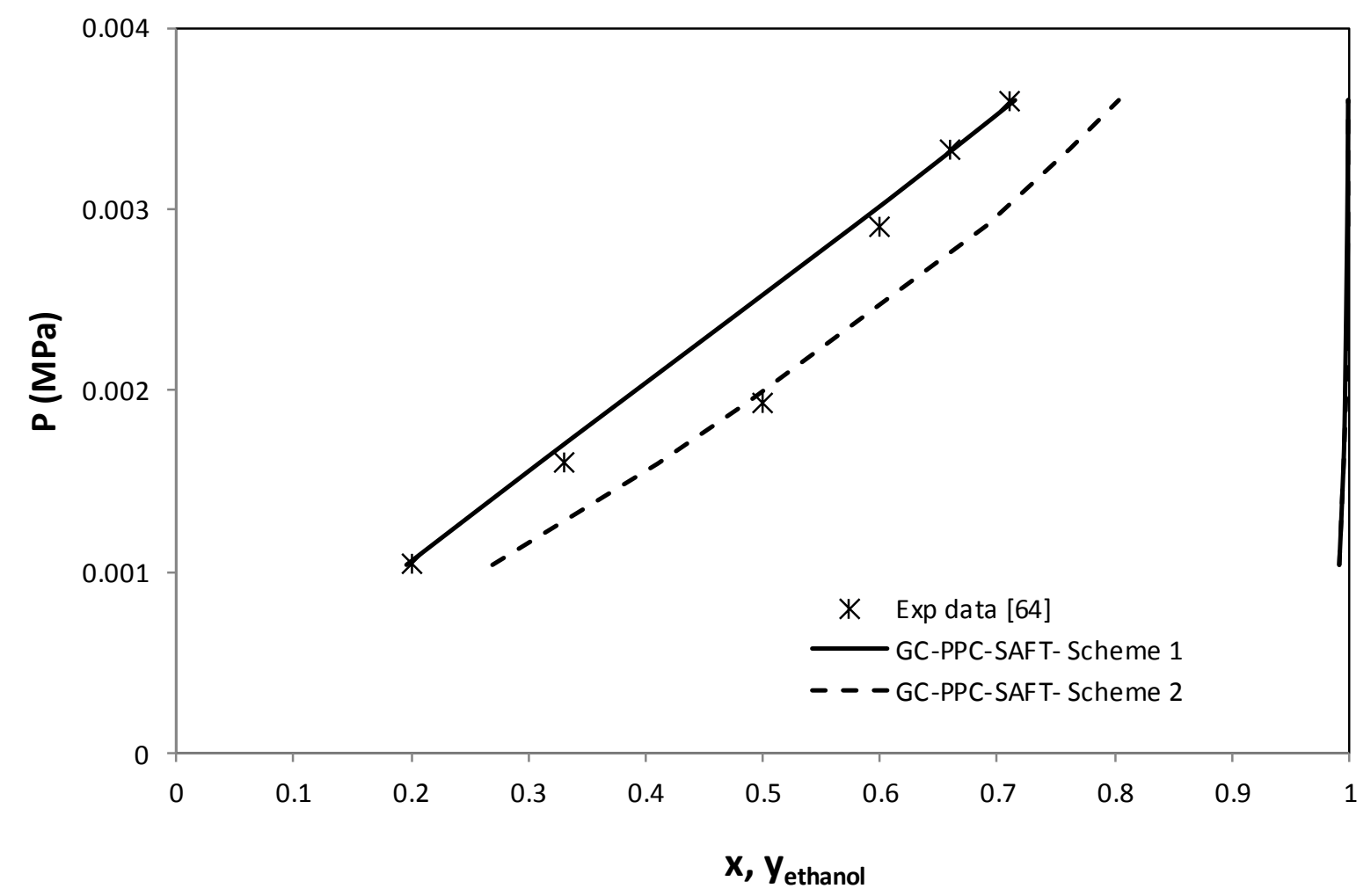

Figure 11. 


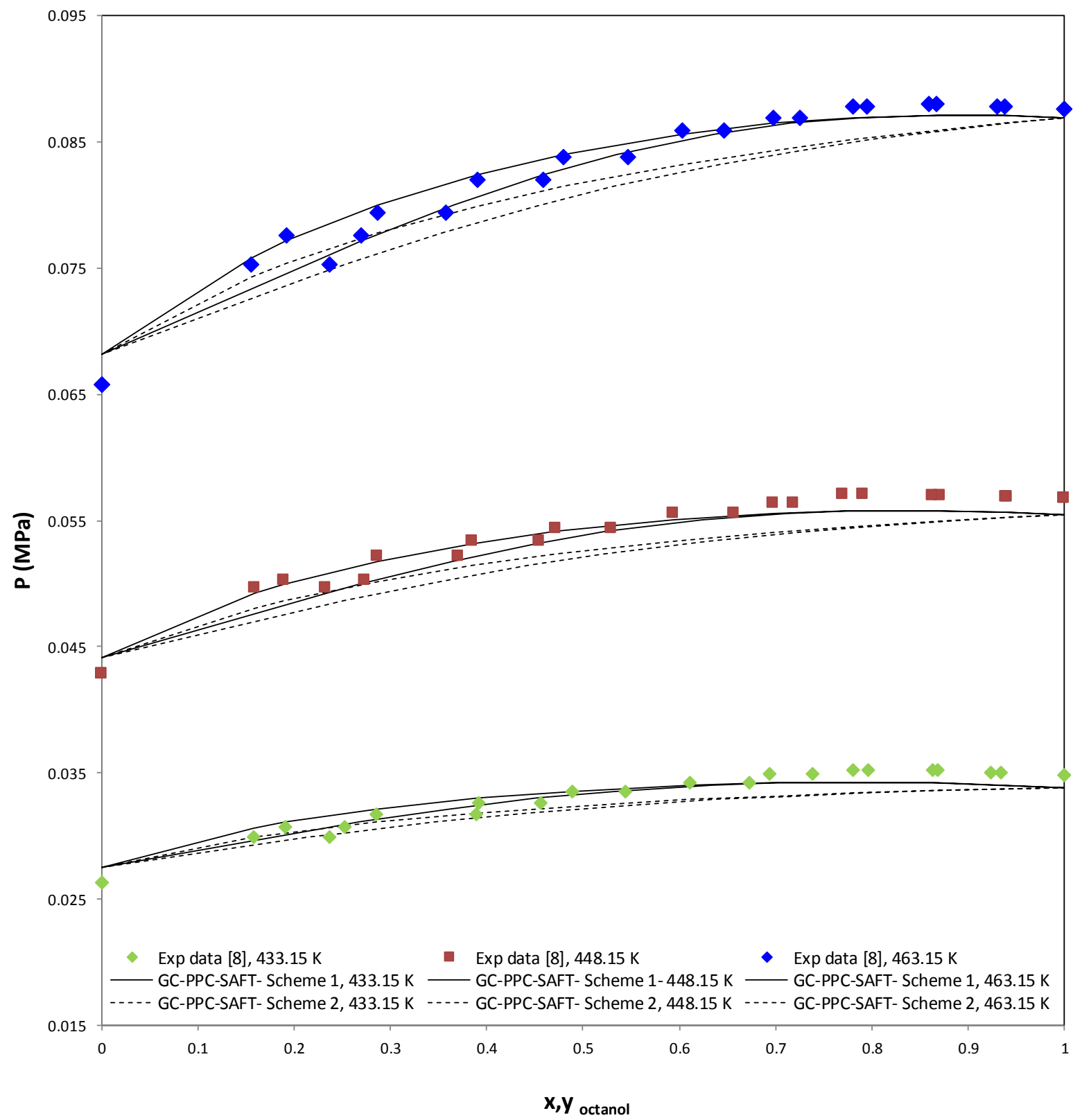

Figure 12. 


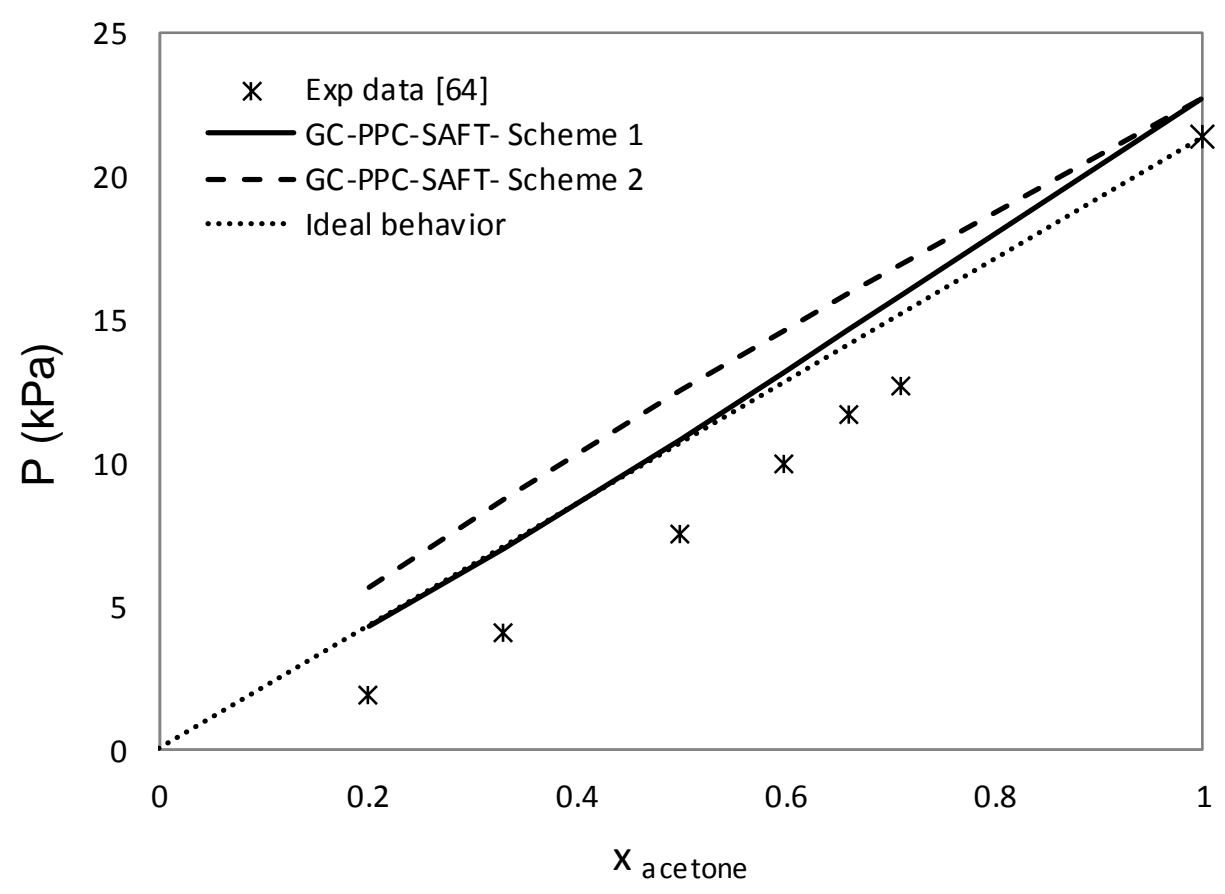

Figure 13 


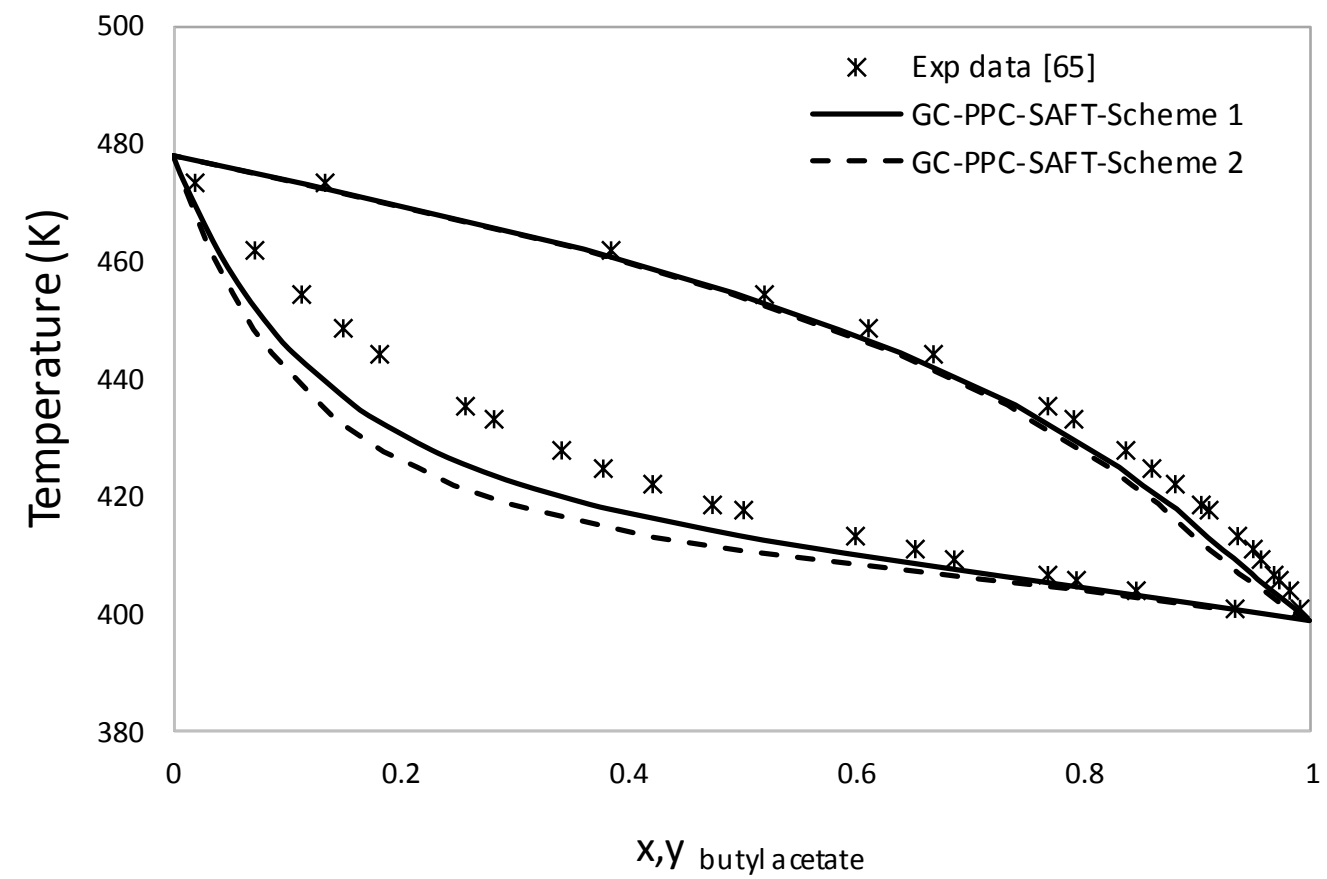

Figure 14. 


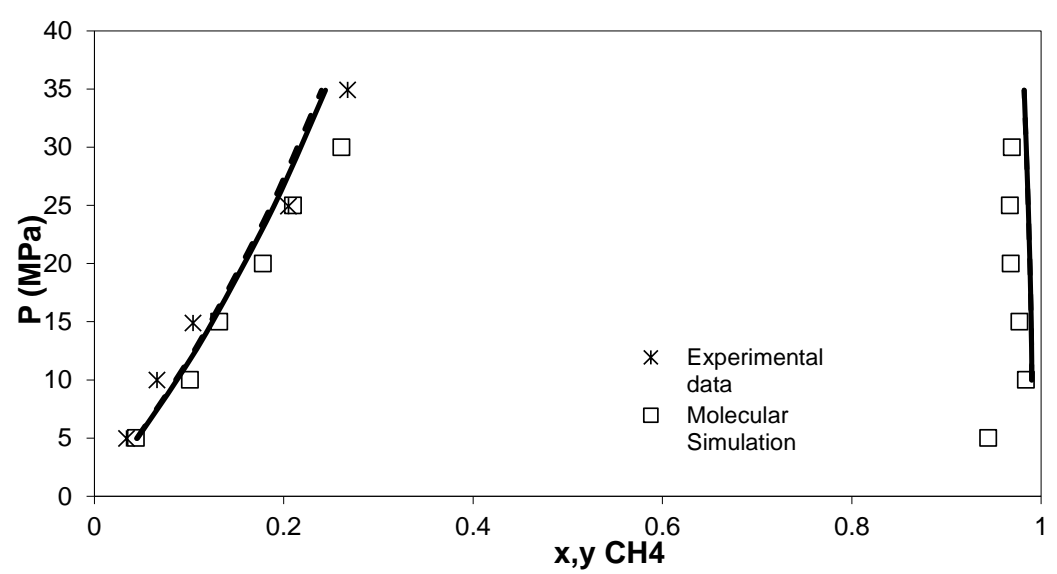

Figure 15. 


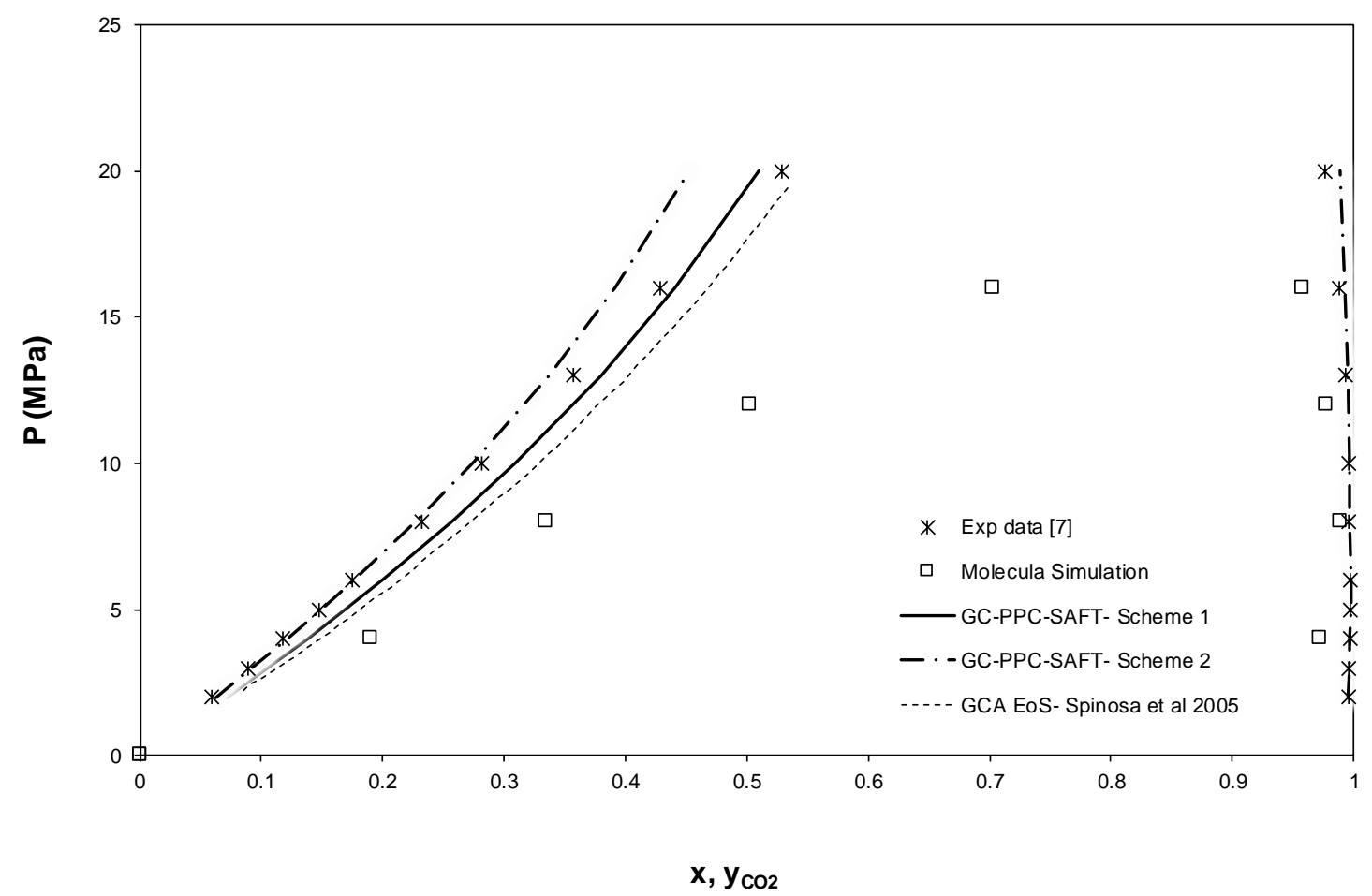

Figure 16. 


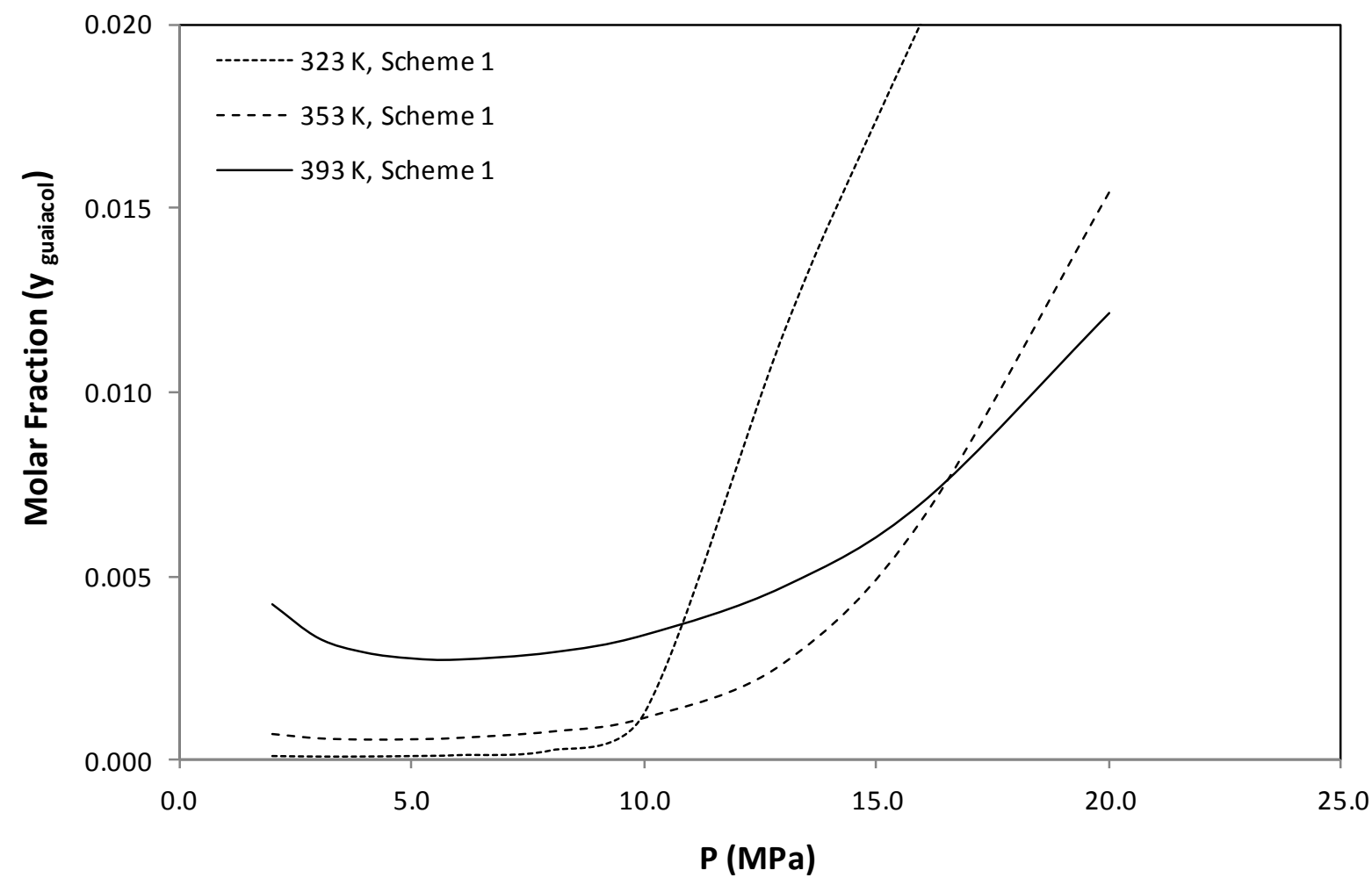

Figure 17. 


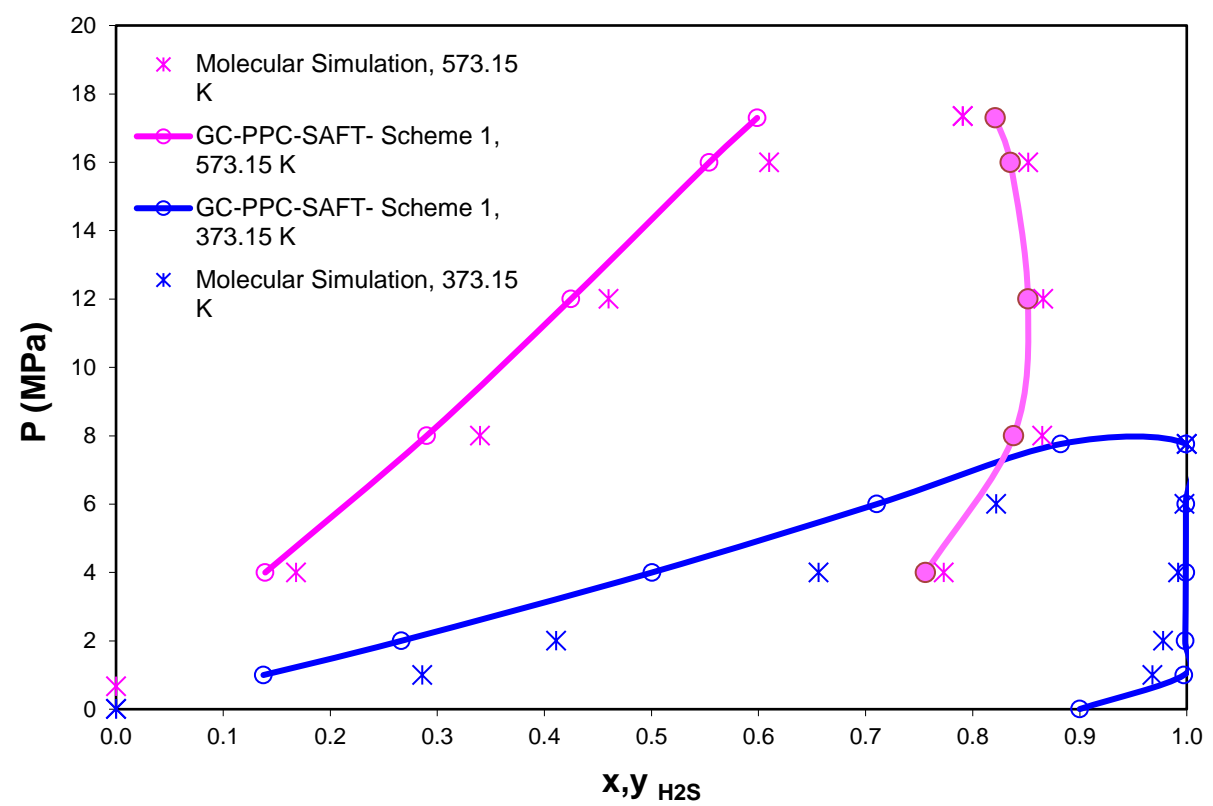

Figure 18. 


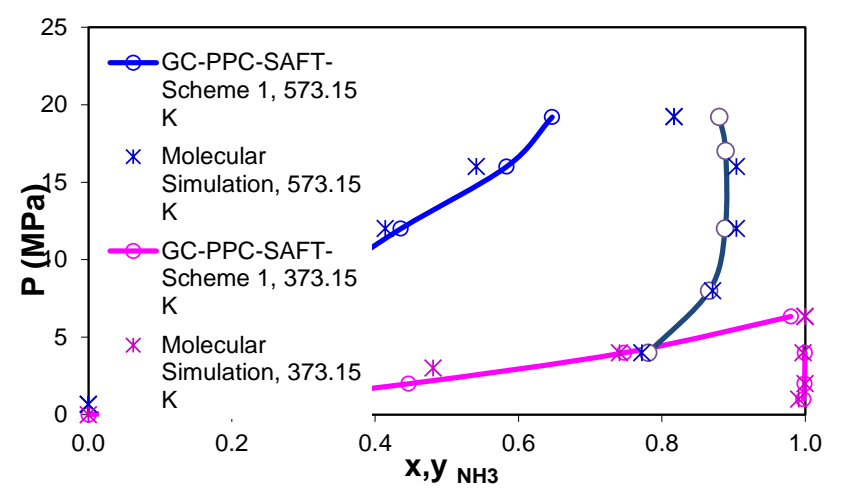

Figure 19. 


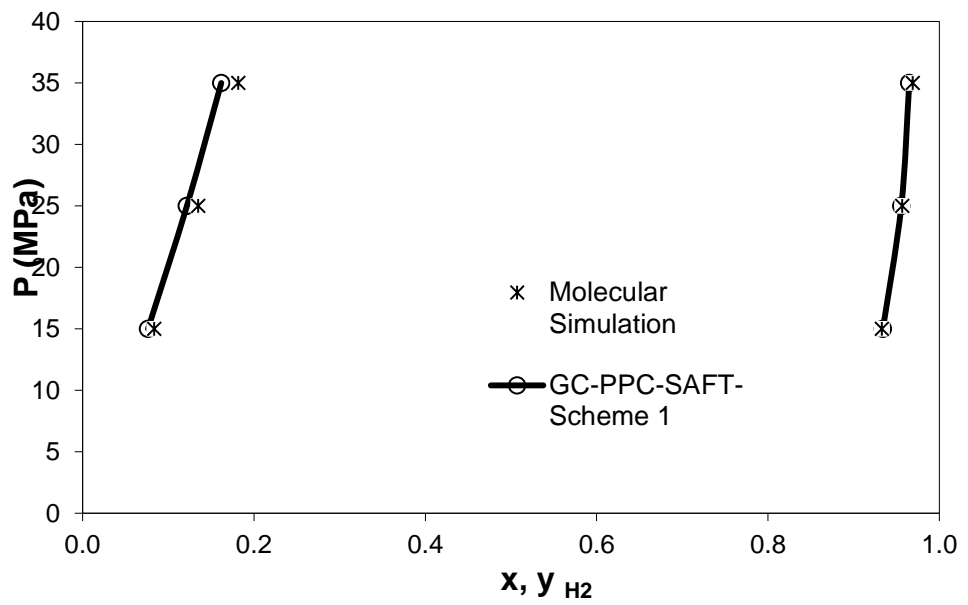

Figure 20. 


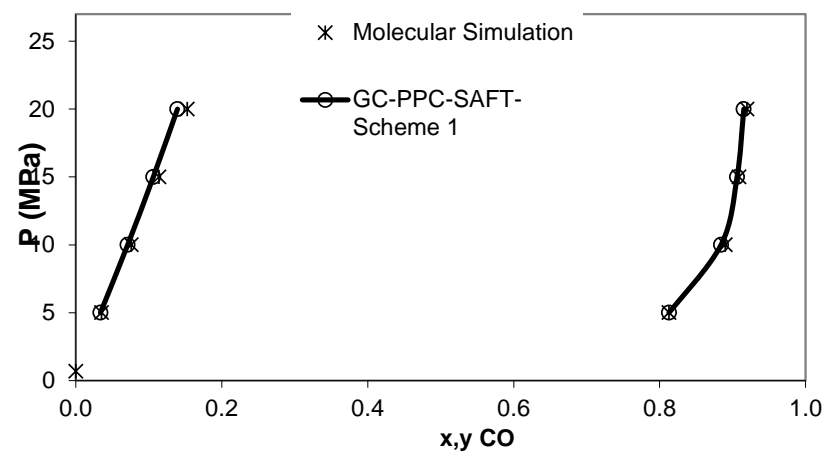

Figure 21. 


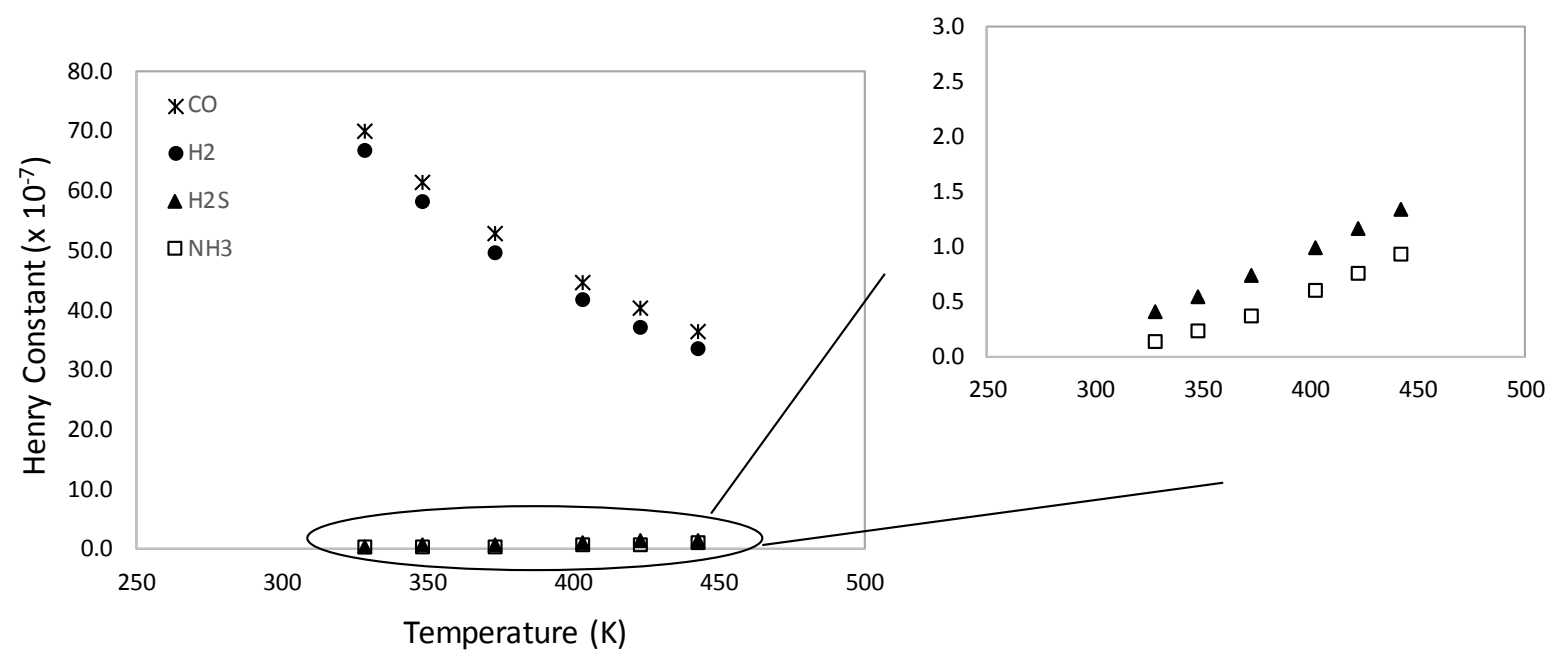

Figure 22. 